\title{
LOS ECOS DE LA CONTRACULTURA EN EL CINE MUSICAL ESTADOUNIDENSE A TRAVÉS DE GODSPELL Y JESUCRISTO SUPERSTAR
}

\author{
Virginia E. Higueras Rodríguez
}

\section{RESUMEN}

La sociedad estadounidense vivió tras la II Guerra Mundial un periodo de bienestar económico que llevó a la estabilidad social. Sin embargo, los eventos políticos harían que las nuevas generaciones se rebelaran contra todo el sistema establecido, cuestionándose a menudo la vigencia del mismo. Coincidiendo con un momento político convulso, los jóvenes creadores romperían los esquemas culturales, que parecían haber entrado en bucle, en el periodo conocido como Contracultura. Ésta será una de las etapas artísticas y culturales más prolíficas, en la que los jóvenes no tendrán miedo a enfrentarse a los principios morales y cuya obra trascenderá más allá de las barreras temporales. La industria cinematográfica vivirá un cambio de paradigma que transformará las tendencias más independientes en verdaderos hitos de la cultura de masas, como fue el caso de Godspell y Jesucristo Superstar.

Palabras clave: Contracultura, Generación Beat, movimiento hippie, cultura de masas, musical estadounidense, religión.

\section{THE ECHOES OF THE COUNTERCULTURE IN THE MUSICAL CINEMA \\ OF THE UNITED STATES THROUGH GODSPELL \\ AND JESUS CHRIST SUPERSTAR}

\section{Abstract}

In the United States took place after the II War World, a period of economic wellness that lead the country towards social stability. Nevertheless, the political events will have made the new generations of American citizens revolt against the establishment, often questioning its validity. In a tumultuous political moment, the young artists would crash the already established cultural scheme, that has been stuck in a loop, in the period known as Counterculture. This would be one of the most prolific artistic and cultural eras when young people were not afraid to confront the moral principles while developing a series of works that would transcend the time barrier. The cinematographic industry would experience a change of paradigm when independent works became hits amongst mass culture, such as Godspell and Jesus Christ Superstar.

Keywords: Counterculture, Beat Generation, Hippie Movement, Mass Culture, American musical, religion. 
Haz que todo suceso sea un acontecimiento de significado histórico y mítico. Conviértete a ti mismo en un símbolo (Jerry Rubin)

\section{EL ORIGEN DE LA CONTRACULTURA}

Hablar de Contracultura implica, no sólo abarcar el despertar juvenil que se vive en los Estados Unidos, sino también las crecientes manifestaciones que se desarrollaron en una Europa que empezaba a recuperarse tras la II Guerra Mundial, especialmente en Francia y Reino Unido. La Contracultura no fue un movimiento uniforme en el tiempo y tampoco se desarrolló en un país exclusivamente. «Los Setentas conforman un fenómeno complejo, difícil de reducir únicamente a ciertas tendencias políticas o sociales [...]. Algo ocurrió, sin importar las fechas exactas. Ese algo, tenía que ver con el comportamiento, la forma de vestir, el lenguaje, la música, y las costumbres sexuales» ${ }^{1}$ (Oppenheimer, 2003: 4).

Siendo los principales focos de esta revolución cultural Francia, Reino Unido y Estados Unidos; fue este último el más influyente frente a los países europeos.

Los años sesenta representan un cambio crucial, 'una discontinuidad'. Desde 1607 hasta 1965, la Historia de Estados Unidos se desarrolla siguiendo 'un patrón cíclico. Así es como lo hicimos hasta que la Great Society lo arruinó todo: no trabajes, no comas, tu salvación es espiritual; el gobierno por definición no puede salvarte; los gobernantes creen en mantenerse en su posición y todas las buenas reformas buscan la transformación' [...]. La Contracultura es una aberración momentánea en la Historia de Estados Unidos que será revisitada como un tranquilo período bohemio en la élite nacional (Frank, 1997: 2).

Se generó así, un movimiento de protesta contra el conocido como american way of life, un modo que, como describe el sociólogo Will Herberg:

Es individualista, dinámico y pragmático. Reafirma el valor supremo de la dignidad del individuo, insiste en la incesante actividad por su parte, ya que no debe descansar nunca, sino esforzarse por avanzar; define una ética independiente, mérito y carácter, y en la que se juzga por logro: 'hechos no creencias' son lo que cuenta (1960: 79).

Esta idea está ya presente en la Declaración de Independencia de los Estados Unidos (1776): todos los seres humanos fueron creados iguales, y están dotados de ciertos derechos inalienables por el creador, cuyo fin último es ir en busca de la felicidad. Precisamente, el modo de vida americano pone de manifiesto que todo ser humano es capaz de progresar en la escala social, sin importar su origen. Haciendo referencia a la industria cinematográfica, encontramos un buen ejem-

\footnotetext{
1 Traducción de los textos originales en inglés realizada por la autora.
} 
plo de esto en los grandes moguls de los estudios, muchos de ellos procedentes de una Europa devastada por la I Guerra Mundial, que galopaba hacia la II, dominada por el nazismo. La mayoría de los creadores de los grandes estudios cinematográficos fueron judíos procedentes de Centroeuropa que crearon las primeras sedes en la Costa Este. Con el tiempo se trasladarían a Hollywood, donde dominarían la gran industria del cine.

En 1933, el demócrata Franklin D. Roosevelt se convirtió en el nuevo presidente de Estados Unidos, siendo el encargado de levantar el país siguiendo una política económica intervencionista, conocida como el New Deal, concebida para luchar contra los efectos de la Gran Depresión. Este programa se desarrolló entre 1933 y 1938 con el objetivo de reformar los mercados financieros y, así, recuperar la economía estadounidense. Sería en este preciso momento cuando empiecen a surgir los primeros argumentos que marcaron el posterior desarrollo de los movimientos contraculturales en los sesenta. Como se recoge en el texto de Barbara Epstein:

Los movimientos de los ańos 30 pueden ser vistos como el punto de partida de la política que se desarrollará en la posguerra: establecieron la importancia de clase, especialmente la de la organización de la clase trabajadora. La experiencia de los 30 puso de manifiesto la relación entre los movimientos de protesta y el estado; fue la presión de la clase trabajadora organizada y sus aliados la que condujo a la creación de un estado del bienestar (1993: 22).

Con la creciente recuperación económica a finales de la década de los treinta, Estados Unidos se ve implicado en la II Guerra Mundial. Mientras tanto, los primeros movimientos pacifistas comenzaban a tomar forma. El Partido Comunista y la izquierda, alimentados por las ideas del movimiento obrero y el New Deal, ayudaron a que la sociedad estadounidense se tornara más democrática. Sin embargo, estos primeros movimientos sociales pronto se radicalizaron, llevando la política hacia el populismo y el feminismo, rodeado de una sensibilidad cristiana que pronto derivó hacia la utopía. «Durante la Guerra y a lo largo de los cincuenta, las organizaciones pacifistas que sobrevivieron, atrajeron a pacifistas radicales que no sólo eran contrarias a la guerra, sino que además eran críticos con la estructura social y cultural» (1993: 28). Estas primeras revoluciones sociales sentaron las bases del movimiento pacifista que nació en los años setenta como respuesta a la participación de Estados Unidos en la Guerra de Vietnam. Como recoge Epstein en su texto Political Protest and Cultural Revolution:

Una generación de pacifistas radicales emergió a partir de la experiencia de la Guerra para desafiar a los cautelosos líderes de los movimientos pacifistas existentes. Las organizaciones más importantes eran las de inclinación religiosa, la Comunidad de Reconciliación y su filial secular la Liga de la Resistencia a la Guerra [...]. Los pacifistas radicales impulsaron la creación de la Conferencia de la No-Violencia Revolucionaria Socialista, una formación de corta vida comprometida con el socialismo, el anarquismo y el pacifismo (1993: 28). 
Si bien los movimientos culturales y los periodos históricos son difíciles de acotar entre una fecha de nacimiento y muerte, muchos autores encuentran el origen de la Contracultura a mediados de la década de los cincuenta, cuando la sociedad estadounidense, ya completamente recuperada después de la crisis económica, empieza a crecer hacia una cultura de masas y un sistema capitalista. Las comodidades económico-sociales en las que esta nueva generación se desarrolló provocaron que gran parte del incipiente mercado capitalista se dirigiera hacia estos despreocupados consumidores que poco conocían las penurias vividas en décadas anteriores.

Como este grupo continuaba sus estudios más allá del instituto en cifras de récord, el fenómeno de jóvenes adultos no vinculados a las rutinas y las responsabilidades adultas, expandieron la cultura juvenil más allá de los años de la adolescencia. [...]. Esta subcultura y su desconexión de la vida adulta tradicional empezaron a criticar seriamente la cultura dominante, incluyendo el consumismo que les había consentido en su infancia (Richardson, 2012: 8).

Muchos autores apuntan que, pese a ser un periodo histórico convulso lleno de movimientos sociales, el punto de partida de ésta se sitúa en 1955, cuando se produce el primer acto contra la segregación racial en Montgomery, Alabama. Esta protesta por parte de los ciudadanos afroamericanos, en busca de reafirmar sus derechos, es quizás el revulsivo que necesitaba una sociedad adormecida tras la II Guerra Mundial.

Los cambios culturales que se identificarían como 'contracultura' comenzaron mucho antes de 1960, con profundas raíces en la bohemia y el pensamiento romántico [...]. Como reacción a la anquilosada economía y estado cultural de los años de la posguerra, casi nadie se dio cuenta de cómo ese contexto -el ámbito económico y la clase media- estaba cambiando a lo largo de la década de 1960 (1997: 6).

Los ańos sesenta se caracterizaron por ser un periodo especialmente combativo a favor de los derechos civiles, la libertad de expresión, la igualdad entre razas, entre hombres y mujeres, y el inicio de los movimientos LGTB. Pudiendo situar así hacia 1969, coincidiendo con el nacimiento del movimiento de liberación de la mujer, el arranque del conocido como movimiento gay, a partir de la revuelta de Stonewall. Como el historiador y activista Martin Duberman describe:

Stonewall marca un hito emblemático en la historia moderna del movimiento gay y lésbico. El suceso de una serie de revueltas a finales de junio y principios de julio de 1969 resultaron en una redada policial en un bar gay de Greenwich Village, 'Stonewall' se ha convertido en sinónimo, a lo largo de los años, de la resistencia gay a la opresión [...]. Los disturbios de 1969 se toman generalmente como el nacimiento del movimiento político de la comunidad gay y lésbica moderna -este fue el momento en el que gays y lesbianas, todos al unísono aceptaron su humillación y reforzaron su solidaridad. Por definición 'Stonewall' se ha convertido en un símbolo empoderador de proporciones globales (Duberman, 1994: XVII). 
Los movimientos contraculturales emergen de los jóvenes y se postulan como una transición generacional presente en todas las manifestaciones socioculturales. Tomando como referencia una de las producciones musicales que mejor reflejan la efervescencia de este periodo, Hair. The American tribal love-rock musical-obra musical original de Gerome Ragni y James Rado estrenada en 1968-, vemos como se teme al movimiento juvenil más radical, donde su protagonista sufre las consecuencias de la Guerra de Vietnam.

\subsection{La Generación Beat}

Como establece Ann Charters, biógrafa de Kerouac, en un país que vivía en la estabilidad económico-social posterior a la II Guerra Mundial, surgiría el germen de la Contracultura:

Era el momento del cambio. A finales de la década de 1950, el país estaba experimentando el despertar de una disidencia radical generalizada, en parte como respuesta a los tumultuosos eventos históricos de la Guerra Fría, con el sangriento esfuerzo de los Estados Unidos para restringir la expansión global del comunismo, y en parte como reacción contra la conformidad autocomplaciente (2001: xx).

Atendemos así al nacimiento de una generación marcada por las tensiones nucleares de la Guerra Fría, la contundente lucha del senador Joseph McCarthy contra el comunismo, las secuelas de la bomba de Hiroshima y el inminente estallido de la Guerra de Vietnam. En este periodo convulso podemos identificar una serie de autores que se erigen como instigadores de una revolución juvenil: Allen Ginsberg, Jack Kerouac, Neal Cassady y William S. Burroughs constituyen el núcleo de la conocida como Generación Beat.

La Generación Beat fue un movimiento literario que surgió entre las comunidades bohemias de postguerra en el Greenwich Village de Nueva York, en North Beach, San Francisco y en Boston. Ginsberg apunta que fue «un grupo de amigos que trabajó de manera conjunta en la poesía, la prosa y la conciencia cultural de mediados de los cuarenta hasta que el término se popularizó a finales de los cincuenta» (Waldman, 1999: xIv) y si bien se define a esta generación especialmente por su literatura, podríamos hablar de una comunidad heterogénea formada por artistas, escritores e intelectuales que crearon simultáneamente en la era del expresionismo abstracto y el jazz bebop a finales de los ańos cuarenta. Al tratarse de un movimiento tan heterogéneo y definitorio de una generación, encontramos en él tintes undergroud o, como lo llamaba Kerouac, subterráneos, siendo además un híbrido entre los bohemios y los hípsters de Nueva York. Podríamos, por tanto, establecer que esta generación surgió a mediados de los cuarenta y se extendió a lo largo de la década de los cincuenta hasta comienzo de los sesenta. Tomando tales dimensiones, fue necesario encontrar un término capaz de englobar tan diversas creaciones y creadores. Es precisamente su carácter híbrido lo que propicia la aparición de varias definiciones a lo largo de la década. 
El primero en designar a este movimiento como la Generación Beat fue el escritor John Clellon Holmes en un artículo publicado en The New York Magazine el 16 de noviembre de 1952, "This is the Beat Generation». La primera acepción de la palabra beat que aparece al buscar su traducción directa al español es golpear y de alguna manera Holmes relaciona a la Generación Beat con este significado. Como ocurre con la Generación Perdida del periodo de entreguerras, los jóvenes de la década de los cincuenta fueron golpeados con violencia contra ellos mismos y contra el muro que constituyó una sociedad que parecía estar sumida en el estatismo, tras la II Guerra Mundial. Para Holmes, la palabra beat «implica la sensación de haber sido utilizado, estar en carne viva. Implica una suerte de desnudez de mente, y, básicamente, del alma» (1952: 10). Holmes no sólo proporciona esta definición, sino que pone además de manifiesto la relación de los jóvenes de ambas generaciones con la espiritualidad. Tanto la Generación Perdida como la Beat fueron resultantes de periodos bélicos anteriores que marcaron profundamente su relación con fuerzas superiores. Holmes establece que, mientras los jóvenes de los ańos veinte estaban ocupados luchando con la pérdida de la fe, la Generación Beat buscaba desesperadamente la existencia de una divinidad. Deja entrever así lo importante que era para esta generación la espiritualidad y su conexión con un plano divino. Esta idea se condensa en la definición presente en el siguiente texto de Kerouac:

Beat no significa estar cansado, o desgastado, tanto como significa beato, la forma italiana para beato; estar en estado de beatitud, como San Francisco, intentando amar la vida, intentando ser sincero con todo el mundo, practicando la resiliencia, la amabilidad, cultivando la alegría del corazón. ¿Cómo puede esto llevarse a cabo en esta locura del mundo moderno de multitudes y millones? Practicando la soledad, caminando contigo mismo de vez en cuando, para almacenar el oro más preciado: la vibración de la sinceridad (1995: 568).

Esta última definición de Kerouac aparece, según escritos de Ginsberg, por primera vez en el año 1959 "para contrarrestar el abuso del término en los medios» (1999: XIV), lo que nos hace cuestionarnos la relación de la Generación Beat con el mundo religioso, que, sin duda, tuvo un gran impacto en décadas posteriores. Prestando atención al texto de Ginsberg encontramos una tercera teoría acerca del origen de la palabra beat como definitoria de una generación, siendo posiblemente la más acertada de las tres. Ginsberg asegura que Herbert Huncke, amigo de Kerouac y perteneciente al círculo literario de los cuarenta, fue el que introdujo el término beat en esta pequeña comunidad que apenas comenzaba su andadura. Esta palabra procedía del argot hip, propio de Nueva York; y si bien en algún momento se usó como sinónimo de encontrarse en la noche oscura del alma y en la niebla de lo desconocido, mucho antes tuvo otros significados más tangibles y cercanos a la realidad, como sin techo o marginado.

En este contexto, la Palabra 'beat' es [...] un término muy utilizado en Times Square: 'Hombre, estoy 'beat', significa sin un lugar donde quedarse [...]. O la palabra puede ser utilizada como en la siguiente conversación: ‘'Te gustaría ir al zoo del Bronx?' 'No, estoy demasiado 'beat', estuve despierto toda la noche'. En 
su uso original en la calle significaba exhausto, en el culo del mundo, esperando algo, desvelado, perspicaz, marginado, solo, espabilado. O como una vez se insinuó, 'beat' significaba acabado, terminado, en la noche oscura del alma o en la niebla de lo desconocido (1999: XIII-XIV).

Entendiendo que se trató de un movimiento profundamente heterogéneo es difícil establecer una de estas tres definiciones como la única y verdadera. En un afán por delimitar con palabras la magnitud de este movimiento, el término beat se utilizó para englobar a hombres y mujeres que frecuentaron los mismos círculos culturales, y que tuvieron un especial contacto con la literatura.

Podríamos decir que el acto inaugural de este movimiento tuvo lugar el 7 de octubre de 1955 en una galería de arte experimental de San Francisco, la 6 Gallery. Allí se reunieron una serie de poetas que decidieron desafiar el sistema académico y la poesía tradicional: Philip Lamantia, Michael McClure, Philip Whalen, Gary Snyder y un joven Allen Ginsberg. Es en este momento cuando, por primera vez, ve la luz el poema de este último Howl for Carl Solomon. Sin embargo, el término beat no apareció hasta dos años después, en 1957, tras la publicación de la novela de Jack Kerouac On the road y la finalización del juicio contra el editor Lawrence Ferlinghetti por publicar los poemas de Ginsberg, condenados en ese momento por su carácter obsceno.

No son sólo los hombres los protagonistas de la Generación Beat, pues hubo también un grupo de mujeres escritoras que trabajó a la sombra de los grandes nombres. «Las mujeres de la Generación Beat, con raras excepciones, escaparon del ojo de la cámara. Se mantuvieron ocultas, escribiendo. Fueron una pieza fundamental para el legado literario de la Generación Beat» (Knight, 1996: 1). En los años cincuenta la mujer estadounidense quedó recluida al ámbito doméstico, como se refleja en el texto de la teórica feminista Friedan: «Las amas de casa de las afueras eran la imagen sońada y la envidia de las jóvenes mujeres americanas» (1963: 18). Muchas de ellas tenían trabajos de asistente o secretaria, que les permitían dar sustento económico a sus jóvenes maridos que asistían a la universidad. Las mujeres beat fueron «rebeldes valientes con talento y con un espíritu creativo suficiente como para dejar atrás 'la buena vida' que prometían los años cincuenta. [...] Nada podría ser más romántico que unirse a un movimiento de individualidad y libertad, dejando atrás el aburrimiento, la seguridad y la conformidad» (3). Todas las mujeres de esta generación compartían las mismas inquietudes que los hombres, «ellas corrieron riesgos, cometieron errores, hicieron poesía, hicieron el amor, hicieron historia. Las mujeres del Beat no tenían miedo de ensuciarse» (3). Eran inconformistas, lucharon contra lo establecido, muchas de ellas no se casaron, criaron hijos birraciales. dejando atrás la establecida como perfecta ama de casa de los años cincuenta. «Su modo de vida iconoclasta iba aparejado con su trabajo literario» (4).

Algunos autores apuntan a que existieron tres generaciones de mujeres beat. La primera, que formó parte de la Nueva Bohemia de la posguerra, sentó las bases de las dos posteriores, rompiendo con las formas literarias más académicas. Nacidas en los años treinta, la segunda generación de escritoras, en la que encontramos autoras como Joanna McClure, Bobbie Louise Hawkins, Lenore Kandel, Elise Cowen, 
di Parma y Kyger, vivió en completa consonancia con los nombres masculinos más destacados de este movimiento. Los textos de las mujeres de esta segunda generación anticiparon la segunda ola feminista que se desarrolló en los años sesenta. «La versión de la individualidad americana de las mujeres beat fue un revulsivo para la liberación personal promulgada en sus escritos. Esto desencadenó un levantamiento femenino centrado en la literatura beat que anticipó la segunda ola feminista» (Johnson y Grace, 2002: 7). Si a la segunda generación se la relaciona con el despertar feminista de los años sesenta, la tercera generación fue precursora de la libertad que se experimentó en el movimiento hippie.

El papel de la Generación Beat fue cuestionar los principios y los valores fundamentales de una sociedad que vivía anclada en el puritanismo. Los beat fueron sin duda los predecesores del movimiento hippie de los sesenta. «En la sociedad moderna Occidental, los valores de comunidad están presentes en la literatura y el comportamiento de lo que se conoce como "generación beat" y que será sucedida por los "hippies"” (Turner, 1969: 112).

A principios de la década de 1960 empezó a gestarse lo que fue el movimiento hippie en el barrio Haight-Ashbury de San Francisco, donde una amalgama de artistas, estudiantes de Berkeley y de la Universidad de San Francisco, así como los drops out y bohemios de la zona de North Beach, conectan, como se recoge en el texto de Moretta:

Los jóvenes americanos que se unieron a la contracultura creían que era mejor dejar todo atrás y 'encargarse de sus asuntos' antes que continuar sobreviviendo o intentando dar sentido a una sociedad quebrada. Los hippies representaban 'una protesta, una declaración de intenciones' [...]. Los hippies eran de valores anti tradicionalistas, anti materialistas; de hecho, anticapitalista (2017: 38).

Los jóvenes buscaban hacerse un hueco en el mundo por ellos mismos. Como el sociólogo Stuart Hall atiende a definir, «el hippie es un "drop out" (salido) del sistema para el que le han estado preparando la familia, la educación y el proceso de socialización: activamente "opta" por seguir el camino "desviacionista" de vida" (1970: 17). Muchos de ellos eran estudiantes de entre 18 y 25 años que decidieron dejar atrás una vida orientada al trabajo, el estatus y el poder. Entendiendo como poder no sólo a la capacidad de ejercer poder sobre otros, sino al económico que lleva hacia el perfecto modelo de vida americano. "En la década de 1960 los hippies se rebelan contra la cultura americana establecida, sus valores y sus prácticas» (Rorabaugh, 2015: 15). Para comprender contra qué se rebelaban los jóvenes de los sesenta, debemos saber en qué creía la sociedad de los años cincuenta. En esa década, bajo el paraguas de la estabilidad económica, nace el Estados Unidos suburbano, de casas idénticas con su correspondiente jardín y bandera en la fachada. Es en este momento cuando la clase media empieza a crecer en las afueras de las ciudades. Siendo profundamente patriótica, abiertamente anticomunista y, en su mayoría, profesaban la religión cristiana o judía, siendo el protestantismo el movimiento que seguía dominando el país. La vida se desarrollaba en torno a la familia, imagen que se había estandarizado a través de la televisión. 
Como método de escape frente a esta perfecta sociedad, los jóvenes encontraron un nuevo modelo de vida en el que todo parecido con la realidad vivida hasta el momento sería una mera coincidencia. Aparecen así las primeras señales de la vida bohemia, donde prima el compartir, el vivir en comunidad y el respeto mutuo. Los núcleos juveniles se convierten así en espacios de experimentación colectiva en los que todos van en busca de lo mismo, encontrar la realidad detrás de su existencia. Las comunas, los gurús, el yoga en grupo y la música psicodélica en ambientes donde las sustancias ayudan a encontrar el éxtasis más allá de la vida terrenal se convierten en un nuevo modo de vida. El movimiento hippie comenzó así a extenderse a lo largo del país, desarrollando un estilo de vida radicalmente opuesto al modo de vida tradicional.

Las comunas, el amor libre, el misticismo y el uso indiscriminado de drogas para expandir la conciencia fueron los pilares básicos sobre los que se erigió este nuevo movimiento. Si bien todo esto cobraría sentido a lo largo de los ańos sesenta, materializándose en el verano del amor de 1967, los «hijos de las flores» no fueron más que los herederos de una revolución que comenzaron los beat. Como establece el autor del texto American Hippies (2015), ambos compartían el deseo de alcanzar la autenticidad y el conocimiento de los valores individuales. Para poder llevar a cabo una tarea de autoconocimiento, los hippies retornaron a la vida en comunidad, de manera que hacían frente al anticomunismo y, como establece Hall, abandonaron el frenesí de la vida moderna.

El arcadianismo pastoral de los hippies marca un retorno a la simplicidad autosuficiente de la comunidad separada que ha hecho una aparición tan fuerte de tanto en tanto en la cultura americana: una visión de que la vida en sus formas y organizaciones más simples puede ser reducida a lo meramente esencial y así es contrapuesta al frenesí, a las necesidades estimuladas y a los anhelos consumistas de la civilización tecnológica moderna; el deseo de recrear, dentro de la América industrial y urbana, la paz y la dulce coherencia de la comunidad tribal (1970:30).

La idea de vida en comunidad va intrínsecamente relacionada con el amor libre, que muchas veces se da también en comunidad. Si bien los hippies ponen de manifiesto que para liberarse de un pasado opresor hay que liberarse también de prejuicios, es el autor Allen Ginsberg el que encuentra en el amor libre la solución a los problemas del mundo moderno. «Tan pronto como cada persona sea libre de amar a otra persona, la sociedad estará curada, la cultura sanada, y el crimen, la violencia y la guerra desaparecerán» (2015: 28). En un país que vive las consecuencias de la Guerra Fría y se prepara para la Guerra de Vietnam, los hippies predican el altruismo y el misticismo, así como la alegría y la no violencia. Con estos valores, cada vez más jóvenes se suman a las filas del movimiento, escapando de la realidad suburbana y acomodada en la que vivían. Como refleja Roszack: «El FBI informó de unos noventa mil jóvenes fugados en 1966. [...] encontrados, a miles todos los años, en las bohemias de las grandes ciudades, desnutridos, pasto de las enfermedades venéreas» (1970: 48). 
Ya desde los tiempos de los beat, como vimos en la definición que hace Kerouac del propio término, los jóvenes de la posguerra presentaban un gusto por los fenómenos místicos y religiosos. Uno de los primeros en manifestarlo fue Allen Ginsberg, que poco a poco fue haciendo la transición hacia el zen y las tradiciones místicas de Oriente, convirtiéndose en uno de los grandes gurús del movimiento hippie. El historiador Theodore Roszak lo define como «el apóstol peregrino cuyos poemas no son más que forma subsidiaria de anunciar la nueva consecuencia que él encarna y las técnicas para cultivarla» (1973: 144). Lo que buscaban era, por un lado, escapar de la oscura realidad que los rodeaba y, por otro, estar en paz con ellos mismos, explorando su ser a todos los niveles. Como Ginsberg, muchos jóvenes comenzaron a viajar hacia Oriente Medio e India en busca de experiencias místicas a través de las cuales llegar al autoconocimiento, rompiendo así con el sistema conformista que generaciones pasadas habían establecido. La religión cristiana era mayoritaria en Estados Unidos, junto con la judía, por lo que buscan alejarse lo más posible de estos modelos.

Los libros sagrados de la religión y misticismo oriental, los libros-códigos eróticos, las figuras de Buddha y de Karma, fragmentos de la filosofía oriental, la adopción del kashdan, el orientalismo simulado del ritual de las «representaciones» de LSD de Leary, la música de Ravi Shankar, la cítara, las danzas sinuosas y culebreantes, los cantos budistas de Allen Ginsberg, todos estos elementos en el ecléctico orientalismo de la vida hippie, representan una vuelta a la contemplación y a la experiencia mística (1970: 27).

Buscaban estar en contacto pleno con la realidad, estimulando los sentidos que la estereotipada sociedad les había bloqueado. Para ello se sirvieron de sustancias alucinógenas también conocidas como psicodélicas. Las virtudes de estas drogas y su uso son descritas en el texto de William Burrough que empieza a circular en 1953, Junkie. Primero los beat, y, más tarde, «los hijos de las flores», comenzaron a experimentar con este tipo de sustancias para alcanzar un estado alterado de conciencia que les permitiera la vivencia de experiencias trascendentales. Los hippies comienzan estando en contra de los avances de la ciencia, por lo que utilizan sustancias presentes en la naturaleza, como la marihuana, la mezcalina, el peyote o el hachís, hasta que descubrieron el poder de la dietilamida de ácido lisérgico (LSD). La marihuana y el hachís comenzaban a recomendarse en libros de cocina de finales de los cincuenta; además, profesores de la Universidad de Berkeley afirmaban que todos los jóvenes debían haber fumado hierba antes de los 20. Como refleja Brown en su texto, las sustancias psicodélicas se convirtieron en un método de escape de la aburrida realidad en cuyo viaje los sentidos se distorsionaban y la imaginación se disparaba.

La filosofía de lo psicodélico, una ferviente creencia de la autorrevelación, los poderes alucinógenos de plantas y semillas y químicos mezclados conocidos por el hombre desde la prehistoria, pero completamente ajeno para la sociedad Occidental [...]. Una alfombra mágica con la que escapara de la aburrida realidad en la que las 
percepciones se intensifican, el sentido se distorsiona, y la imaginación es permanentemente deslumbrada por visiones extáticas de la verdad tecnológica (1967: 2).

Hacia 1967, el movimiento hippie estaba muriendo. En octubre de ese mismo año se desarrolló la marcha contra la Guerra de Vietnam en el Pentágono y por primera vez en la historia los hippies acudían en masa a un acto eminentemente político. Fue en ese momento cuando se dieron cuenta de la realidad: la sociedad no estaba dispuesta a aceptar el cambio. Poco quedaba de los hippies que habían iniciado el movimiento. Las barbas, los pantalones de campana, las flores y el arte psicodélico trascendían a su significado original. Los verdaderos hippies se reunieron en julio de ese mismo año en San Francisco para enterrar de manera simbólica el flower power.

\subsection{Dios baja A la Tierra: Músicos folk y predicadores de Masas}

Durante los años de la Contracultura, la espiritualidad y el misticismo se apoderaron de jóvenes que se abrían paso hacia un mundo nuevo. Buscaban, en las culturas orientales, alejarse lo más posible de las creencias consideradas tradicionales. Sin embargo, será en este momento cuando comiencen a aparecer, a lo largo y ancho de Estados Unidos, nuevas comunidades cristianas. El catolicismo, que hasta entonces había sido una de las ramas del cristianismo minoritarias en ese país, cobrará gran relevancia. Nos encontramos así con nuevas comunidades que, sirviéndose de la música y la oración colectiva, marcarán un antes y un después en las prácticas religiosas. Será entonces cuando los predicadores procedentes de Latinoamérica se erijan como gurús de la juventud que busca alejarse de las prácticas tradicionales. Si bien el catolicismo no había gozado de una gran devoción hasta el momento, los cambios en el Concilio Vaticano II y la introducción de nuevas formas de celebrar la fe generan una nueva y atractiva manera de vivir en comunidad, que se asemeja a las experiencias del movimiento hippie. La música folk y la oración irán de la mano en un momento en el que encontraremos cantautores dedicados única y exclusivamente a desarrollar música religiosa.

En una época en la que prolifera la búsqueda del yo y las experiencias trascendentales a través de las creencias orientales, el catolicismo, una religión anclada en el pasado, con el latín como lengua universal, debe adaptarse a la sociedad o morir. En 1959, con el anuncio del Concilio Vaticano II, pudieron realizarse los cambios que les darían a los cristianos católicos un nuevo lugar en Estados Unidos. Aun siendo uno de los credos más liberales dentro del país, nunca se consideró como propio, ya que fueron los inmigrantes irlandeses los que lo llevaron consigo. En un territorio donde habían aparecido los mormones, diferentes sectas, creyentes en Satán, los católicos no eran considerados una religión principal, como sí lo era el protestantismo. Por ello fue tan importante el Concilio Vaticano II, que, como refleja el texto del historiador musical Cusic, introdujo en sus cultos la música contemporánea:

El catolicismo ha tenido un desarrollo aparte del protestantismo americano, y ha tenido si no ninguno, muy pocos efectos en la recuperación del cristianismo en 
América. Su estructura rígida controlada por el Vaticano deja a la fe prácticamente inmutable, mientras que las religiones del protestantismo americano estaban cambiando dramáticamente. Sin embargo, el mayor cambio se produjo con el Concilio Vaticano II que llevó a la introducción de la música contemporánea en las 'misas folk' de mediados de los sesenta (2002: 269).

La primera misa folk tuvo lugar en 1964 bajo el nombre de Mass for Young Americans. Los efectos de esta carismática renovación hicieron que las misas pasaran de ser un rito de espaldas a los fieles a uno desarrollado directamente hacia las personas, que ahora podían establecer una relación directa con Dios. Como afirma Cusic, «los católicos sentían que podían tener una relación directa con Cristo y las misas se centraron más en la gente [...]. Esto llevó a la formación de grupos católicos y la aparición de cantautores que pudieran escribir el material necesario para las misas» (2002: 273). La incorporación de estas canciones al culto hizo que su forma cambiara completamente, ya no consistían en sentarse, arrodillarse y ponerse en pie cuando fuera necesario. La música invitaba a bailar en círculos, cogidos de la mano, acompańados por una guitarra y en ocasiones percusión que llevaba al baile interpretativo. "Las canciones folk católicas motivaban al naturalismo y la familia, a la libertad de creencias universal. Su religión no trata sobre doctrinas o el catequismo, sino sobre un espíritu generalizado [...]. Estas canciones podían ser cantadas fácilmente por metodistas, luteranos o presbiterianos» (2003: 80). Las canciones evitaban hacer mención directa a la figura de Jesucristo o los santos católicos, y poseían un carácter universal de paz y vida en comunidad, por lo que no sólo eran dominio de los católicos, sino que otras ramas del cristianismo también las adoptaron.

En los años sesenta atendemos a un resurgir de la música folk, entendiendo ésta como parte del folclore estadounidense que se relaciona con las tierras al oeste del río Mississippi y los cowboys. Sin embargo, la música que surge en esta década tiene tintes del blues y sonidos procedentes de las culturas indígenas americanas. No podríamos entenderlo sin la imagen de Bob Dylan, que tuvo un papel importante en el desarrollo de la música de la Contracultura, siendo el impulsor del resurgir folk en la década de 1960. "La inspiración del folk era la utopía y la inocencia» (Coupe; 2007: 83-84), siendo un género ampliamente aceptado, que para los católicos fue muy sencillo tomar como referencia. No sólo contaba con una gran cantidad de artistas que se habían sumado a éste, entre los que destacaron Johnny Cash, Simon \& Garfunkel, Neal Young o Leonard Cohen, sino que sus letras, en su mayoría con origen literario, eran narraciones o poemas, lo que lo convirtió en un género muy asequible para todos los públicos.

Mientras Estados Unido vivía este nuevo apogeo católico, en América Latina comenzaban su andadura los predicadores, que no tardarían en cruzar la frontera para sumarse a los ya existentes gurús. Será entonces cuando aparezca la teología de la liberación, constituida por una mezcla de elementos protestantes y católicos. Los primeros escritos que aparecen sobre esta nueva forma religiosa son del sacerdote peruano Gustavo Gutiérrez Merino. Como aparece reflejado en el texto del teólogo Leonardo Boff: 
La teología de la liberación y del cautiverio ha nacido en un contexto de Tercer Mundo y en el seno de cristianos que se han dado cuenta del régimen de dependencia y de opresión que viven sus pueblos. Partiendo de un compromiso liberador inspirado en su propia fe cristiana, intentaron una praxis concreta en sus iglesias y en la sociedad, que se reflejó en una práctica teórico-teológica distinta de la tradicional y que tomó el nombre de teología de la liberación (1978: 5).

Latinoamérica se caracterizará en la década de los cincuenta y los sesenta por ser un continente en vías de desarrollo que sufría la dominación de los grandes países que abrazaban el capitalismo, como es el caso de Estados Unidos. Los sectores más deprimidos y los países menos desarrollados fueron los más afectados por esta situación, siendo en este contexto en el que se habla de teología y praxis de la liberación. Leonardo Boff reflexiona sobre las características de la teología de la liberación, y sobre cómo se erige la Iglesia y, por tanto, los sacerdotes como únicos instrumentos de salvación. El papel que éstos desarrollaron adscribiéndose a la misma podría ser más cercano al del gurú que al del propio sacerdote. La nueva teología hace hincapié en el carácter humano de la figura de Jesús. Cristo se presenta como verdadero hombre que, siendo un privilegiado, no sólo se acerca a los pobres, sino que se hace pobre y funda la Iglesia para anunciar su liberación.

La idea clave de la teología que comprende la historia humana como única historia de liberación-salvación y de opresión-perdición significa que no hay portadores exclusivos de liberación y de opresión. Todo y todos en la historia son señales e instrumentos de salvación y de perdición. No es específico de la Iglesia traer la liberación a un mundo que vive bajo todas las formas de alienación, de pecado y de opresión. La salvación-liberación está siempre presente en la historia. La ofrece Dios por Jesucristo a todos los hombres desde el comienzo de la historia (1978: 96).

En un periodo de continuos cambios sociopolíticos, muchos de los jóvenes que habían encontrado en el movimiento hippie una manera de dejar atrás la perfecta vida estadounidense, buscando la experimentación espiritual, llegaron a las comunidades cristianas. Los jóvenes de la Generación Beat encontraron en las creencias orientales la liberación del espíritu y la búsqueda de la verdadera razón de ser. Una vez que estas influencias llegaron al país, aparecieron los nuevos gurús, que, considerándose expertos en materias espirituales, guiaban a las masas hacia elevados estados de conciencia. Las influencias latinoamericanas de la teología de la liberación generaron un gran impacto en estas nuevas comunidades. Entendiendo que todos somos responsables de nuestra liberación espiritual, la idea de la existencia de un solo mesías comienza a cuestionarse. 


\section{NUEVAS VÍAS CREATIVAS DEL MUSICAL EN ESTADOS UNIDOS}

Como movimiento social, la Contracultura tuvo un gran impacto a todos los niveles dentro de la vibrante cultura estadounidense de los ańos sesenta. Tanto la literatura como la música sentaron las bases de la narrativa que se desarrolló tanto en el teatro más experimental de Nueva York como en las películas que, poco a poco plagaron los cines de los suburbios estadounidenses. Como medio de comunicación, el cine permitió que el pensamiento más liberal diese el salto desde los suburbios neoyorquinos a la gran industria hollywoodiense. A pesar de que los principales movimientos tuvieron lugar a lo largo de la década de los sesenta, muchas de las películas con una mayor carga contracultural no aparecerán hasta entrados los setenta.

En el caso del cine musical nos encontramos que, en las décadas en las que se encuadra la Contracultura, poco quedaba de la boyante industria que floreció en los años treinta. Con el declive del sistema de estudios moriría la gran maquinaria de los musicales a principios de los años setenta. El musical, el género escapista que había gozado de un éxito inigualable en los años siguientes al final de la I Guerra Mundial, entró en «la década de 1970 con la penosa distinción de haber ayudado, más que ningún otro género, a propiciar la crisis financiera de 1969-1971» (Cook, 2000: 209) de la industria cinematográfica; ya que, como apunta Cook, para su recuperación y vuelta a las grandes pantallas, los estudios quisieron retomar la espectacularidad de grandes musicales como Sonrisas y lágrimas (Robert Wise, 1965), lo que los llevó a la bancarrota, tras la pérdida de más de sesenta millones de dólares entre 1967 y 1970. De esta manera, podríamos considerar que ese filme fue el canto del cisne del musical clásico de Hollywood. Algunos autores apuntan que la caída del género, en ese preciso momento, se debió a la efervescencia musical que se vivía en la calle. La imposibilidad de encontrar un único género que fuera capaz de mover a las masas propició una fuerte inestabilidad a la hora de crear nuevas películas que cosecharan el éxito del que, treinta años atrás, habían gozado las películas protagonizadas por Fred Astaire y Ginger Rogers. A pesar de que la caída del musical se coloca a mediados de la década de los sesenta, lo cierto es que ya desde la anterior el género había perdido interés para el público, teniendo que recurrir a las nuevas estrellas del rock, como Elvis, para de alguna manera continuar explotando el filón. Todo ello coincide con el estallido del fenómeno fan, primero con el Rey del Rock y a continuación, a nivel mundial, con The Beatles, viendo la industria en ellos una fuente de ingresos. Mientras la sociedad estadounidense vivía momentos de tensiones políticas, con la Guerra Fría, la de Corea, así como el inminente conflicto en Vietnam, las major aprovecharon el furor que causaban los nuevos géneros musicales para atraer a los jóvenes a las salas. Estas películas carecían de buenos guiones, en su mayoría eran historias sencillas que se utilizaban para llevar a la gran pantalla las inquietudes de los jóvenes estadounidenses. Hollywood intentó así que el género que había enamorado a los espectadores décadas atrás no muriera en los momentos más difíciles de la industria. Estas producciones pronto se agotaron, pues la situación social que se experimentó en Estados Unidos a lo largo de los 
años sesenta era demasiado importante como para que las salas proyectaran películas banales; y el público demandaba dosis de realidad.

Mientras que en las pantallas el cine musical no fue capaz de mantener la producción de décadas pasadas, los teatros de Broadway y del Off-Broadway se llenaban con nuevas producciones, lo que nos hace pensar que quizás el problema al que se enfrentaba la industria cinematográfica era mucho mayor que una crisis económica tras la caída en picado del género. Necesitaba encontrar nuevas narrativas que llegaran a los espectadores que mayoritariamente acudían a las salas, la juventud. Mientras los teatros más alternativos de la Costa Este se llenaban de obras experimentales que, poco a poco, conseguían ser transferidas a la avenida teatral más popular de Nueva York, las productoras hollywoodienses, desesperadas por levantar la industria, recurrieron a las adaptaciones de los grandes musicales de Broadway. De modo que, a principios de los sesenta, se estrenaron películas basadas en algunos que ya habían visto la luz sobre los escenarios a lo largo de la década anterior, como es el caso de West Side Story (Robert Wise, 1961), Gypsy (Mervyn LeRoy, 1962), My Fair Lady (George Cukor, 1964) y Sonrisas y lágrimas. Estos dos últimos se produjeron con la intención de que tanto la Warner como la Fox recuperaran las sumas de dinero que habían perdido al producir películas multimillonarias que las habían acercado peligrosamente a la quiebra. En el caso de la Fox, se sirvieron del último musical de Richard Rogers y Hammerstein para recuperar su inversión en una de las últimas grandes superproducciones históricas del estudio, Cleopatra (Joseph L. Mankiewicz, 1963). Los musicales tradicionales no conseguían los beneficios con los que Hollywood pretendía volver a la época dorada. Tras la imposibilidad de crear nuevos filmes que atrajeran público a los cines, vieron como única opción adaptar los grandes musicales de la escena al ámbito cinematográfico. Todo ello coincidía con un momento histórico un tanto turbulento en el que Estados Unidos vivía sumido en una revolución juvenil interna, que atacaba directamente a la estabilidad del país, así como una política exterior delicada, influida por la Guerra Fría y la Guerra de Vietnam, encontrando así en los grandes musicales de Broadway el mejor método para escapar de la realidad. Es especialmente llamativo que a lo largo de los sesenta no encontremos ninguna película de este género que se acerque a las preocupaciones juveniles. Sin embargo, proliferaron los musicales de grandes números, generalmente con un componente romántico, pero, ante todo, tramas en las que se mantenía el estereotipo estadounidense al que precisamente se enfrentaban las grandes masas en las calles de Estados Unidos. No sería hasta 1979 cuando el musical de la Contracultura por excelencia, Hair, llegase a las pantallas. Con el entierro del flower power a finales de la década de los sesenta, las productoras cinematográficas parecen volver a ponerse en marcha, para por fin, tras una década de silencio, tomar conciencia de la revolución cultural que había experimentado el país.

A partir de ese momento, el género musical se vio obligado a buscar un nuevo público y, para ello, fue necesario acercarse lo más posible a la cultura juvenil. Aparecen nuevos creadores, nuevos compositores y directores que se habían formado en los años más vibrantes de la Contracultura. Se produce así el cambio que la industria necesitaba para sobrevivir, y la Contracultura se convertiría, de la noche a la mañana, en un fenómeno de masas. Se utilizó el cine como medio para hacer crítica 


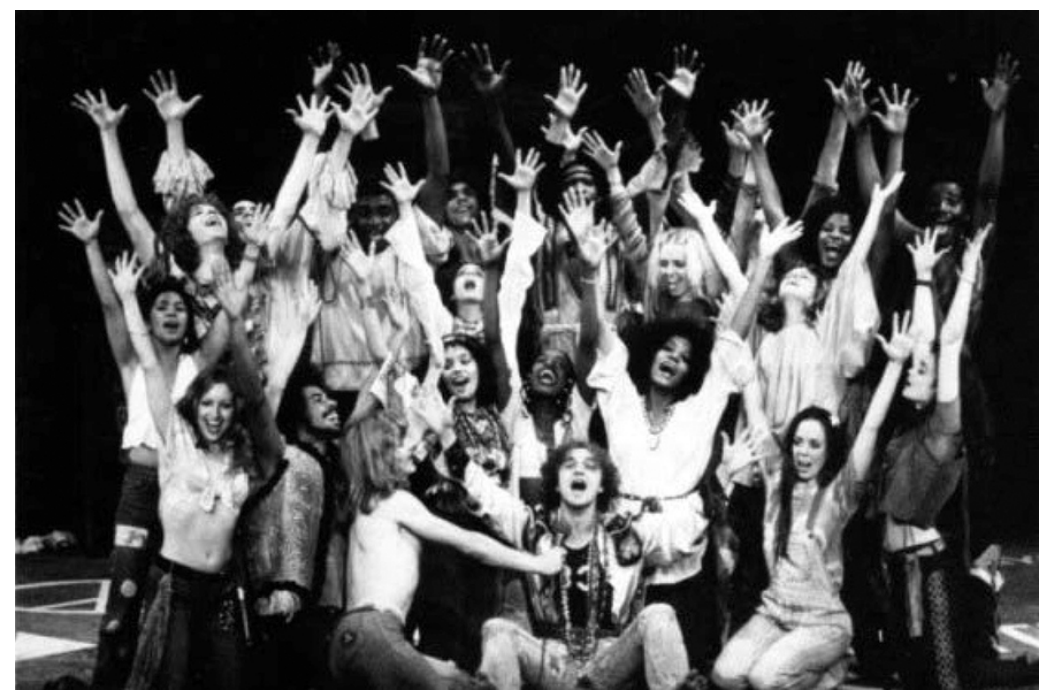

Imagen 1. Elenco original de Hair en Broadway, 1968.

social; ya no se teme, como en décadas pasadas, que la juventud conozca el comunismo, las drogas psicodélicas o los efectos de la Guerra de Vietnam en la población estadounidense. Mientras que en décadas atrás todo vestigio subversivo habría sido censurado, en ésta era por primera vez celebrado, no sin ciertas reticencias. Nuevos filmes aparecieron, en los que se retrata la sociedad de la más pura psicodelia y la música rock, pero, sin embargo, de alguna manera se sigue trasmitiendo el mensaje de peligro frente a los actos radicales que tuvieron lugar a lo largo de la década. Los personajes protagonistas, impulsores del cambio y la revolución en películas como Hair (1979), The Rocky Horror Picture Show (1975) y Tommy (1975), acaban siendo castigados. Es así como el cine tiene la capacidad de llegar a las masas y mostrar los cambios que vive la sociedad, pero sin dejar de lado el carácter moralista que lo acompaña desde sus orígenes.

Como ocurrió con los musicales que llegaron a las pantallas a lo largo de la década de los sesenta, Hollywood siguió dependiendo de adaptaciones de obras teatrales. En estos ańos no se generaron nuevos musicales pensados y creados exclusivamente para su estreno cinematográfico; por ello, la mayor revolución se dio en los escenarios del Off-Braodway a finales de la década. Será en ese momento cuando la música rock apareciese por primera vez sobre los escenarios, como apunta Cerechiari, de manos de la producción creada por James Rado y Gerome Ragni, Hair, The American Tribal Love/Rock Musical (imagen 1).

Las cronologías del musical coinciden en identificar en Hair un [...] punto de inflexión en la larga historia de la comedia musical [...]. Con este espectáculo inusual [...] el rock irrumpe por primera vez en la banda sonora de un espectáculo 
de Broadway, abriendo, aparentemente, el género hasta entonces secular de la calle 42 de Nueva York a las nuevas sugerencias de los aspectos reminiscentes, tímbricos, melódicos e instrumentales de la música juvenil (2017: 282).

Este musical es conocido como la primera ópera rock dentro de la producción de teatro musical; sin embargo, no presenta las características puramente operísticas que aportó el británico de formación clásica, Andrew Lloyd Webber a sus obras a principios de los setenta. Sin embargo, sienta el precedente que siguieron, a partir de ese momento, desarrollando los nuevos libretistas y compositores que se sumaron al musical contracultural.

Hair se convirtió en un hito no solo por las cualidades experimentales de su concepción y su dirección, sino también por su extraordinaria forma de mezclar el rock y el estilo del musical de Broadway, que anteriormente habían sido considerados excluyentes mutuamente. Sin ninguna duda, Hair era único en numerosos aspectos. Fue el primer musical de Broadway dedicado a la cultura hippie de la década de 1960; el primero en incluir desnudez, el primer musical aclamado por la crítica y comercialmente exitoso en Broadway que dependía exclusivamente de una instrumentación rock; $y$, como resultado, el primero en incorporar elementos de la música rock en toda su partitura (Wollman, 2006: 12).

Por fin, tras años de ignorar la cultura juvenil, el musical se rindió a ella, introduciendo en sus canciones ritmos del rock progresivo que comenzó a desarrollarse a principios de los sesenta como una extensión de la Contracultura y la ideología del movimiento hippie.

Las bandas proto-progresivas de la década de 1960 jugaron un papel directo en la escena contracultural, mientras que las principales bandas del rock progresivo de la década de 1970 llevaron a su audiencia de masas hacia una extensión de la contracultura post-hippie. El contenido de las letras es sobre todo una forma de expresión (a veces directa, pero a menudo velada) de la ideología de la contracultura (Maca, 1997: 13).

Se genera así una masa tan heterogénea como la sociedad del momento, no dejando atrás ninguno de los aspectos con los que pudiera identificase su público potencial. Mientras la propuesta escénica se ha mantenido casi inmutable a lo largo de las décadas, la adaptación cinematográfica es mucho más comedida. Es significativo como, a diferencia de las obras procedentes de los teatros londinenses que llegaron a las pantallas casi a la vez que se estrenaban en el teatro, esta adaptación se prolongó hasta diez años en el tiempo. A pesar de ser estrenada en una época de revolución social, su lenguaje gráficamente obsceno, la presencia de sexo simulado y la desnudez ocasional lo llevaron en 1970 a los tribunales, y tras el juicio, durante las funciones previas en Boston, decidieron no estrenar. Era, además, considerado un musical antipatriótico, a pesar de que «no hay nada en las canciones, el libreto, o la puesta en escena que indique que los chicos son antiamericanos, colectiva o individualmente. Simplemente, les entristece ver en lo que se ha convertido América» (Jones, 2003: 250). 


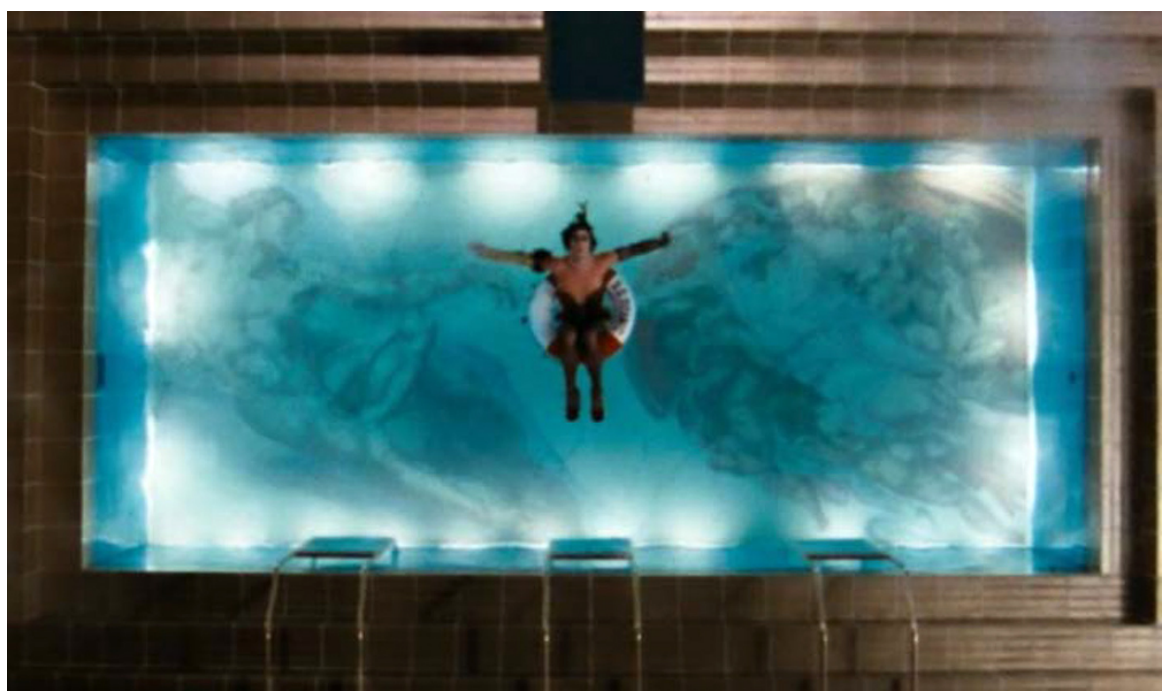

Imagen 2. Fotograma de The Rocky Horror Picture Show, con La Creación de Adán de Miguel Ángel. Capilla Sixtina, ca. 1511.

Mientras Hair es el musical que mejor reflejó los años del movimiento hippie y su música se acercó de una manera más prominente a los diferentes estilos que inundaban las calles, no es la obra con la que se suele relacionar esta revolución social. Cuando hablamos de musical cinematográfico contracultural, la primera película con la que se relaciona este término es The Rocky Horror Picture Show (Jim Sharman, 1975) (imagen 2). Sin embargo, ésta fue estrenada a mediados de la década de los setenta, y estaba basada en el musical teatral The Rocky Horror Show que Richard O'Brian había puesto sobre las tablas de los escenarios de Londres en 1973. Tratando de establecer una cronología en el desarrollo cinematográfico de los musicales de la Contracultura en Estados Unidos, nos encontramos que las primeras adaptaciones que se vieron en las pantallas eran de origen británico, siendo la primera de ellas Jesucristo Superstar (1973, Norman Jewison). Este filme, basado en la obra original del compositor Andrew Lloyd Weber, se convirtió en la primera película que reflejó, no sólo la actitud juvenil del movimiento hippie, sino la importancia de las creencias religiosas para los jóvenes de la Contracultura.

A ambos lados del Atlántico el teatro musical de principios de los años setenta se vio plagado de obras en las que se cuestionaban las creencias religiosas. Después de que Hair rompiera el hielo, incorporando la música más popular a una producción teatral, poco a poco se le fueron sumando nuevas creaciones que se planteaban la vigencia de las tradiciones establecidas por una sociedad que ya no los representaba. Esto llevó a muchos autores a mirar al pasado, y evaluar y reestablecer los valores morales que un día habían sido impuestos por el cristianismo. A finales de 
la década anterior hubo un resurgir de la fe, aparecieron los gurús, las nuevas comunidades cristianas en Estados Unidos, y los teólogos de la liberación en Latinoamérica. Todos estos grupos reexaminaron las creencias del pasado, en busca de una religión para los jóvenes del momento. Por primera vez en mucho tiempo, se toma la Biblia como el texto básico sobre el que construir las obras musicales, que, casi como si de una novela se tratase, asemejan la figura de Cristo a la de los jóvenes que se levantaron contra lo establecido.

Como ha ocurrido a lo largo de la historia, el cine musical se nutre de las obras que anteriormente habían tenido éxito sobre los escenarios. Éstos fueron los casos de Jesucristo Superstar, que se considera la primera ópera rock de la historia, y Godspell (David Greene, 1973), uno de los musicales más experimentales, que sigue palabra a palabra el Evangelio según san Mateo; ambas llegaron a los cines estadounidenses al mismo tiempo. A pesar de tener su origen a kilómetros de distancia, tanto los jóvenes británicos como los estadounidenses tenían las mismas inquietudes, las mismas preguntas sin respuestas y las ganas de experimentar que la Contracultura había sembrado en ellos.

\section{JESÚS EN TIEMPOS DE LA CONTRACULTURA: LAS PROPUESTAS DE GODSPELL Y JESUCRISTO SUPERSTAR}

El rock, el folk y los sonidos populares poco a poco remplazaron los sonidos clásicos de las bandas sonoras de los teatros más populares de la Costa Este de Estados Unidos. Éste es el caso de Godspell, que se estrenó en el teatro Cherry Lane en el Off-Broadway en 1971, tras un proceso creativo experimental, y Jesucristo Superstar, estrenado al mismo tiempo en el teatro Mark Hellinger de Broadway. Ambos musicales exploran la vida y muerte de Jesús en un momento en el que la juventud se cuestiona una de las religiones más extendidas a lo largo y ancho del país. Las comunidades cristianas comenzaron a proliferar en años de la Contracultura, explorando la Biblia, y muchas de ellas se sirvieron de la música para predicar la palabra de Jesús, testigo que recogieron estos nuevos creadores.

Mientras nuevos musicales florecían en la Costa Este, a orillas del Pacífico la industria cinematográfica esperaba las adaptaciones de estos musicales para poder tomar nuevamente las riendas de la industria. Tanto Godspell como Jesucristo Superstar llegaron a las pantallas en 1973. Dos musicales que exploraban la vida y muerte del Mesías se veían las caras en las pantallas de los cines estadounidenses. A pesar de poseer una línea argumental muy similar, nos encontramos con dos películas totalmente diferentes. Ambas fueron obras pioneras. La primera por la forma de tratar las escrituras y su utilización de la música folk; la segunda, por tratarse de la primera ópera rock de la historia del teatro musical. Y esto se debe en gran medida a los creadores que encontramos tras cada una de las producciones. Mientras Godspell tiene sus orígenes en la capital teatral estadounidense, Jesucristo Superstar ve la luz en la escena londinense.

La cronología del estreno teatral y el cinematográfico no son las únicas coincidencias que encontramos en estas obras. Andrew Lloyd Webber, creador de Jesu- 
cristo Superstar, y Stephen Schwartz, autor de Godspell, nacieron en marzo de 1948, creciendo y formándose en los ańos más importantes de la Contracultura. A pesar de haberse formado, cada uno a un lado del Atlántico, la expansión que tuvieron los movimientos contraculturales desde Estados Unidos a Europa salpica su vida y su posterior obra. Es así como este movimiento cultural traspasó fronteras y se convirtió, quizás no al mismo tiempo, en un revulsivo para las capas juveniles de la sociedad. A través de estos dos musicales podríamos establecer las diferencias entre la cultura musical que se generó en ambos países, mientras Godspell se mantiene más cercana a los sonidos propios del folk utilizado por las comunidades cristianas, en Jesucristo Superstar encontramos sonidos más psicodélicos, similares al rock británico que florece a finales de los sesenta de mano de bandas como The Who o Pink Floyd. Si bien a nivel formal encontramos estas diferencias en las bandas sonoras de ambos musicales, los dos autores comparten una formación musical clásica muy similar, lo que los llevó a desarrollar simultáneamente proyectos que coincidieron en tiempo y forma en los escenarios y las pantallas.

Andrew Lloyd Webber, a pesar de que su vida había girado en torno a la música, llegó a entrar en la universidad para cursar Historia. Su aventura universitaria no duraría mucho, pero a lo largo de su producción queda plasmada su fascinación por los relatos históricos. En 1965 comenzó a trabajar con el letrista pop Tim Rice, que lo acompańaría a partir de este momento. Juntos crearon su primera canción pop, Down Thru'Summer, para Ross Hannam, cuya melodía reutilizarían como tema principal en su popular musical Evita, estrenado en 1978. Su carrera comenzó como compositores de música pop, pero, en 1968 Lloyd Webber y Rice consiguieron estrenar lo que para ellos era una cantata, Joseph and the Amazing Technicolor Dreamcoat, que se convertiría en lo que podríamos establecer como el primer musical de su carrera. A pesar de que esta obra ha pasado a la historia como un musical al uso, en su origen era una pieza de tan sólo 22 minutos que se representaba como un concierto dramatizado. Con la estabilidad económica que les proporcionó esta creación, se lanzaron a componer las canciones de lo que sería, en 1970, el álbum conceptual de Jesucristo Superstar.

El tándem Lloyd Webber y Rice (imagen 3) siguió componiendo y estableciendo la ópera rock como su sello de identidad. Hablamos de ópera rock, ya que los musicales que crearon tenían las características de las óperas clásicas. Andrew Lloyd Webber, que había crecido escuchando Tosca, La Bohème y había presenciado a la gran María Callas sobre los escenarios de Londres, trasladó las características operísticas a sus creaciones, apareciendo, así, musicales que utilizaban los ritmos más populares sin una sola línea de diálogo, en los que, como si de una ópera clásica se tratara, se suceden los números de los solistas con grandes baladas, acompañados por temas en los que el coro es el protagonista. Con estas características, su evolución lógica los llevó a crear los musicales como álbumes conceptuales que, eventualmente, se llevarían a escena. Sin embargo, a la hora de trasladar esta idea a la pantalla nos encontramos con una película que recuerda más a una sucesión de videoclips que a un musical cinematográfico al uso. La narración depende completa y absolutamente de los números, la música y la letra de las canciones. 


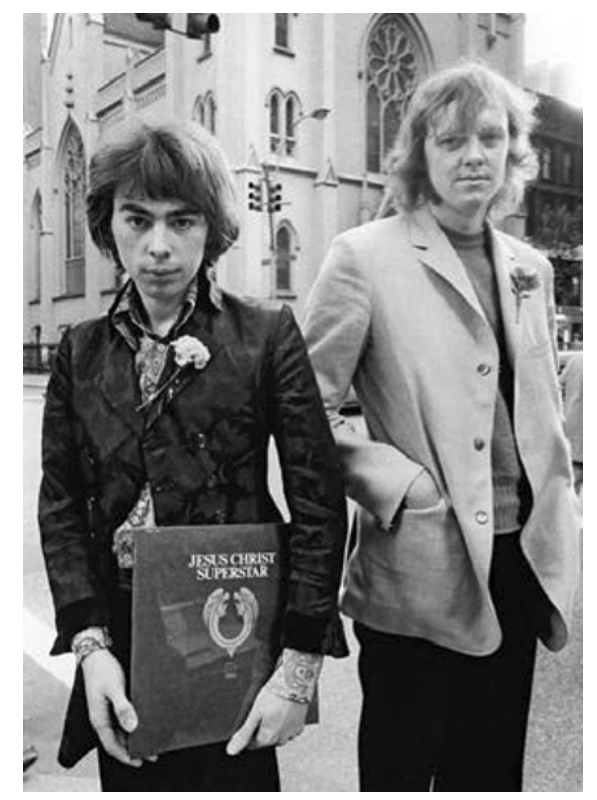

Imagen 3. Andrew Lloyd Webber y Tim Rice ca. 1970.

Al otro lado del Atlántico, en Long Island, había nacido Stephen Schwartz, que, desde una temprana edad, no sólo mostraba facilidades para los idiomas, aprendiendo rápidamente a hablar francés, sino que su pasatiempo favorito era escuchar música clásica. Su primer contacto con ésta fue a través de la obra de Boris Gudonov, y "pronto la ópera se convirtió en uno de sus géneros musicales favoritos [...] que tomaría como modelo para sus musicales Childresn of Eden y Wicked» (De Giere, 2008: 6).

A diferencia de Andrew Lloyd Webber, Schwartz continuó su formación acudiendo a la Universidad Carnegie Mellon, en la que entró, con tan solo 16 años, en 1964. En esta institución comenzó como estudiante de teatro, pero pronto hizo el cambio y termino en 1968 con un título en Dirección Escénica. En sus años allí comenzó a desarrollar, junto con otro estudiante de música, Ross Strauss, lo que se convertiría en 1972 en su musical Pippin. En esta época escribió también una ópera en un acto, Voltaire and the Witches, recuperando las raíces operísticas que se dejarían ver a lo largo de su producción. Una vez que terminó la universidad, se dirigió a los grandes productores de Nueva York, con la esperanza de que Pippin viera la luz.

Tras su terrible decepción, al no conseguir financiación para llevar a los escenarios su primer musical, conoce el texto de otro alumno de Carnegie Mellon, John-Michael Tebelak, que, basándose en el teatro de lo pobre de Grotowski y en el teatro del absurdo, había creado The Godspell. Ésta era una obra en la que alumnos de interpretación de la propia universidad, a partir de juegos de improvisación, 

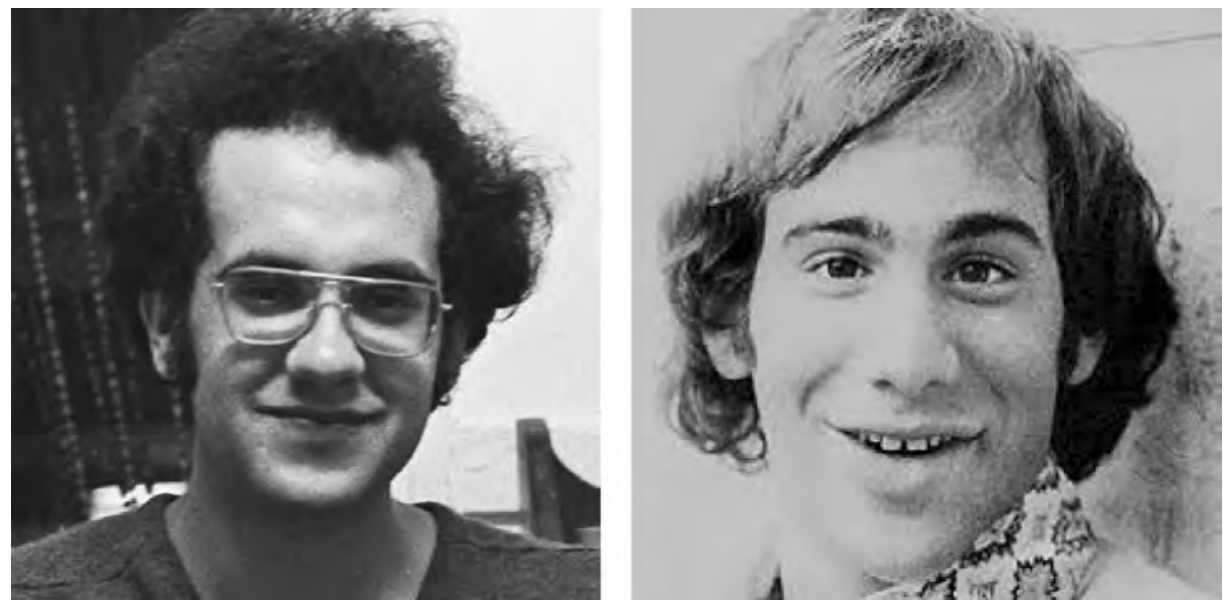

Imagen 4. Stephen Schwartz y John-Micahel Tebelak ca. 1969.

ponían en escena los Evangelios. Schwartz y Tebelak (imagen 4) llevaron la nueva versión, como musical, al teatro Cherry Lane, en el Off-Broadway, en 1970. Tebelak, de tradición presbiteriana, y Schwartz, de origen judío, trabajaron en el texto y las canciones de una obra que seguía, casi al pie de la letra, el Evangelio según san Mateo. Para poner música a esta obra de teatro pionera, Schwartz recurrió al texto del Evangelio de san Mateo, así como se sirvió también de diferentes himnos y salmos que adaptó para acompañar un texto en el que se suceden las parábolas. Ésta es quizás la mayor diferencia que presenta Godspell frente Jesucristo Superstar: mientras la segunda narra los últimos días de la vida de Cristo, la primera se utiliza como un catecismo, en el que poco a poco se representan las enseñanzas que san Mateo extrae de las obras de Jesús. Además, mientras que Lloyd Webber incluye todos los personajes que recoge la Biblia, los doce apóstoles, María Magdalena, Poncio Pilato, Caifás y Herodes, de una manera más sencilla y rayando lo naíf, Tebelak y Schwartz sólo cuentan con diez protagonistas que desarrollan toda la acción. Por ello, aunque las similitudes son mayores que las diferencias, nos encontramos ante dos obras distintas.

Los títulos de ambos musicales son utilizados como una manera de diferenciar las distintas narraciones: en la obra Lloyd Webber y Rice, queda patente que el protagonista de la narración es Jesucristo, elevado a un estatus de estrella de rock. El propio título nos avanza la naturaleza musical que posee, llevándonos a pensar que nos vamos a encontrar con los ritmos más populares del rock progresivo. En el caso de Godspell (imagen 5), se nos presenta con un juego de palabras: por un lado, se utiliza la palabra en inglés gospel, que significa evangelio, pero se le añaden ciertas modificaciones, de modo que se mezclan las palabras God, es decir, Dios, y Spell como hechizo o encanto. Podríamos llegar a pensar que, utilizando este juego 


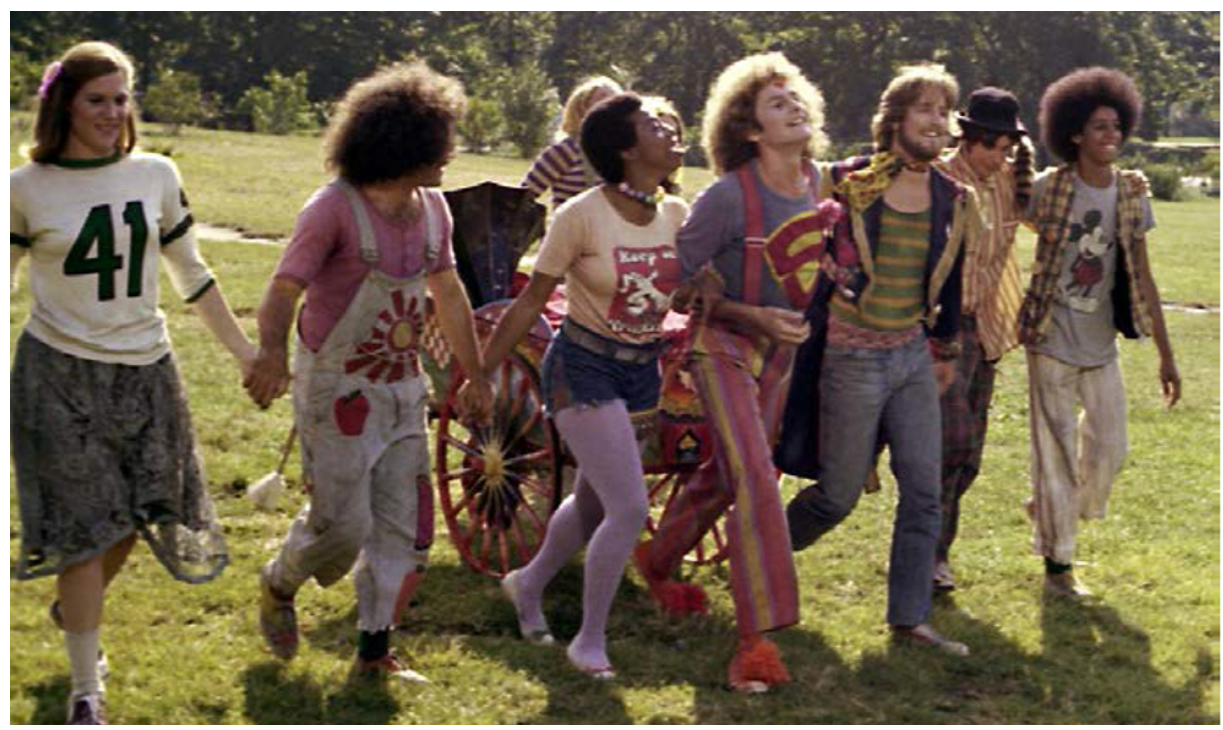

Imagen 5. Fotograma de Godspell, Jesús y sus seguidores.

de palabras, nos encontramos ante una crítica a la capacidad embaucadora de las palabras neotestamentarias en boca de los nuevos profetas surgidos a lo largo de la década que abarcó la Contracultura. Sin embargo, esta película funciona como un catecismo para el espectador, de modo que nos trasmite las enseñanzas a través de las parábolas. Más allá de la representación de la última cena y la crucifixión, los personajes, que al comienzo no tenían relación entre ellos, van adquiriendo un sentimiento de comunidad del que desean hacer partícipe a la sociedad.

A diferencia de este filme, Jesucristo Superstar (imagen 6) se presenta como una narración fiable de los últimos días de la vida de Jesús, en los que encontramos los episodios claves para entender su muerte como el Mesías del Nuevo Testamento. Recordando a las últimas superproducciones bíblicas que se llevaron a cabo por los estudios en la década de los cincuenta, Jesucristo Superstar perpetúa el modelo de narración clásica que encontramos en filmes protagonizados por otros personajes bíblicos, como podría ser el caso de Moisés en Los Diez Mandamientos (The Ten Commandments, Cecil B. DeMille 1956). En esta película se suceden los episodios que llevarán a Jesús ante Poncio Pilato y de ahí a la cruz. La resurrección no se incluye en el filme, de manera que podríamos pensar que nos encontramos ante un Jesús de carne y hueso que nada tiene que ver con el ser divino que se presenta en las Escrituras. De esta manera, se consigue distanciar al espectador de una narración neotestamentaria tradicional, para cuestionarse la mortalidad del rebelde apodado como el «rey de los judíos». A diferencia de Godspell, esta obra cuenta con un elenco de actores mucho mayor, y los personajes que aparecen se identifican 


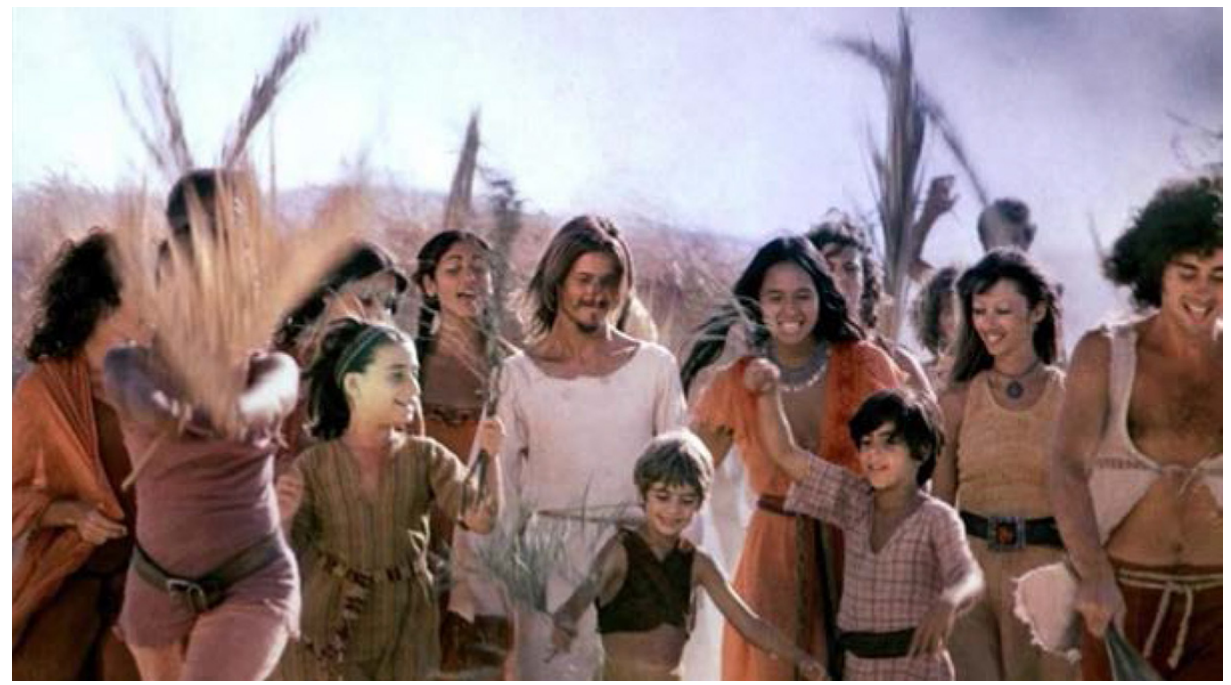

Imagen 6. Fotograma de Jesucristo Superstar. Entrada de Jesús en Jerusalén.

directamente con los que aparecen en el Nuevo Testamento. Como núcleo central podríamos colocar a la congregación de discípulos, integrada en este caso por los doce apóstoles, entre los que destacan las figuras de Judas y Pedro. Este último se presenta como un joven un tanto indeciso que sigue al Mesías, pero, al igual que ocurre en los Evangelios, niega tres veces cualquier relación con él, cuando teme ser apresado. Por otro lado, Judas hace las veces de narrador, es éste el que inicia el musical, cuestionando la dirección que está tomando la vida de Jesús y, como en el caso de Godspell, se distancia progresivamente de la comunidad. Judas se plantea qué es lo que realmente persigue Jesús y cómo poco a poco se ha ido alejando de las bondades que proclamaba, para dejar paso al ego impulsado por la fama. Otro de los discípulos destacados es Simón, que insta a Jesús a la lucha en determinadas ocasiones para levantarse en armas contra los romanos. En este filme, María Magdalena no aparece como un discípulo reconocido, como ocurre en varios relatos del Nuevo Testamento y algunos Evangelios Apócrifos, que le dan un importante papel en los últimos momentos de la vida de Jesús. En este caso, Lloyd Webber y Rice la representan siguiendo la creencia popular que la identificaba como una prostituta enamorada que siguió al Mesías fielmente hasta el final de sus días.

Todos los personajes poseen características fuertemente humanas que los alejan de la narración divina y que los coloca, a menudo, en un plano espiritual elevado. Judas no es sólo el encargado de traicionar a Jesús por dinero, sino que intenta protegerlo del fin que le espera, y como sabemos no puede soportarlo y acaba quitándose la vida. Pedro tiene miedo una vez que apresan a Jesús, por lo que niega toda posible relación con él para evitar ser juzgado. Simón, ante la adversidad, encuentra 


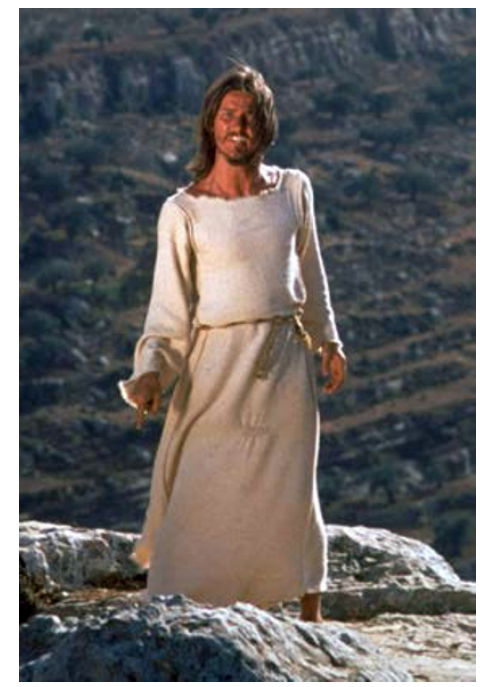

Imagen 7. Ted Neeley como Jesús en Jesucristo Superstar.

en la lucha la mejor respuesta frente a las amenazas de los romanos. Por otro lado, el Nazareno no sigue el estereotipo bondadoso que se perpetúa en las representaciones de su vida, es un personaje ambicioso que comprende el impacto de sus palabras en una comunidad que lo sigue fielmente; la fama se apodera de él y antes de que se dé cuenta se siente abrumando porque todo el mundo quiere algo del proclamado Mesías. Ante esta situación va en busca de Dios para que le responda a su desesperada pregunta, ¿por qué yo? Pareciera que lo que en los Evangelios se trasmite como una bendición, para este Jesús es un castigo que lo lleva a su muerte. Una vez que es condenado se pregunta hasta el último momento por qué debe morir, por qué Dios lo puso en la Tierra si su final era acabar en la cruz -en esto recuerda mucho al Cristo de Kazantzakis-. Podríamos llegar a pensar que Jesús es el verdadero afectado por una conspiración contra su persona, cuando ha conseguido el éxito debe morir, porque se está convirtiendo en una persona demasiado poderosa enfrentándose tanto al propio sanedrín como a Roma, recordemos que será ajusticiado como sedicioso. Caifás, Poncio Pilato y Herodes intentan frenar su creciente control de las masas; sin embargo, no son ellos los que deciden que muera en la cruz, sino los propios judíos. Podríamos ver en Jesús la representación de los jóvenes que se veían abocados a la muerte en el campo de batalla de Vietnam, pues muchos de ellos, como Jesús, no regresarían de su experiencia. Jesús muere en el desierto, donde quedará olvidado, la juventud estadounidense volverá para convertirse en parias sociales.

Mientras que los personajes de Jesucristo Superstar poseen una mayor relación histórica (imagen 7), debemos mencionar que en Godspell, a pesar de tratarse de una película de temática religiosa, los personajes no tienen una relación clara con 
los que aparecen en las Escrituras. Los únicos personajes que atendemos a diferenciar son Juan el Bautista/Judas y Jesús, mientras que lo que podríamos identificar como discípulos adquieren el nombre del actor que los interpreta. Todos ellos se nos presentan al comienzo de la narración como personas normales que llevan una rutina de trabajo que se ve interrumpida por la llamada de Juan el Bautista, que hace las veces de pescador de hombres, y los va congregando. Entre ellos se encuentran una bailarina de ballet sumida en las continuas repeticiones dentro de una sala de ensayos, una actriz que sale huyendo de una audición al ver la ingente cantidad de jóvenes casi clonadas a las que se enfrenta, y una joven que mientras sirve cafés lee el Ulises de James Joyce. Estos primeros minutos reflejan la realidad de una juventud que se siente atrapada en una sociedad que parece no detenerse nunca. En estas primeras secuencias no localizamos al personaje de Jesús, que aparece casi por obra de magia cuando todos han abrazado el cambio que necesitaban.

Como si el tiempo se detuviera, todos ellos acuden a la llamada del Bautista, que los espera en la fuente de Bethesda Terrace, en pleno Central Park, donde, tras ser bautizados, se transforman en una suerte de payasos que mantienen las modas de la época, los pantalones de campana, las flores en el pelo y los estilismos multicolores derivados del movimiento hippie. Su indumentaria contrasta con la que se ve en las primeras imágenes del filme, donde se presentan las calles de Manhattan en tonos grisáceos, desde el negro del asfalto, el gris de los edificios y la paleta monocromática de los trabajadores que plagan las aceras. Esta película, quizás por su localización en la Gran Manzana, se apoya en mayor medida en la cultura de masas que empezaba a proliferar en Estados Unidos. Manhattan se convierte en un gran patio de recreo en el que por un día, los diez jóvenes acuden a la llamada del Bautista, y, convertidos en seguidores de un mesías, escapan de la realidad.

Podríamos interpretar este filme como una visión metafísica en la que se cuestiona la vigencia de los modelos sociales que se habían impuesto tras la segunda Gran Guerra, en la que pareciera que los problemas sociales si no se tratan no existen. El movimiento hippie impulsó la necesidad de compartir y vivir en comunidad y en comunión unos con otros, el amor libre no fue más que la necesidad de encontrar el soporte necesario en el otro. Se genera así una marea de jóvenes que luchan juntos por un cambio sociopolítico. Diez años después, este filme se apoya en la figura de un mesías para trasmitir sus anhelos de cambio. Así, Jesús (imagen 8) aparece identificado como una especie de superhéroe, casi como si del superhombre de Nietzsche se tratara, que lleva una camiseta de Superman una vez que es bautizado. Estamos ante un mesías que se aleja del personaje evangélico que en numerosas ocasiones encontramos en los relatos de su vida y muerte; generalmente, se trata de un hombre joven que no tiene demasiada relación con sus discípulos, más allá de su papel como guía. En este caso, el personaje de Jesús es mucho más cercano y su calidez humana nos hace reflexionar sobre el origen del Mesías, desmitificando la figura del hijo de Dios enviado a la Tierra. Desde un primer momento, a diferencia de otros relatos que colocan a Jesús como el mesías elegido, vemos como es bautizado por el Bautista, junto a los discípulos que deciden seguirlo. Éste es quizás uno de los momentos que más desapercibidos pasan cuando se decide narrar la vida y muerte de Jesús. 


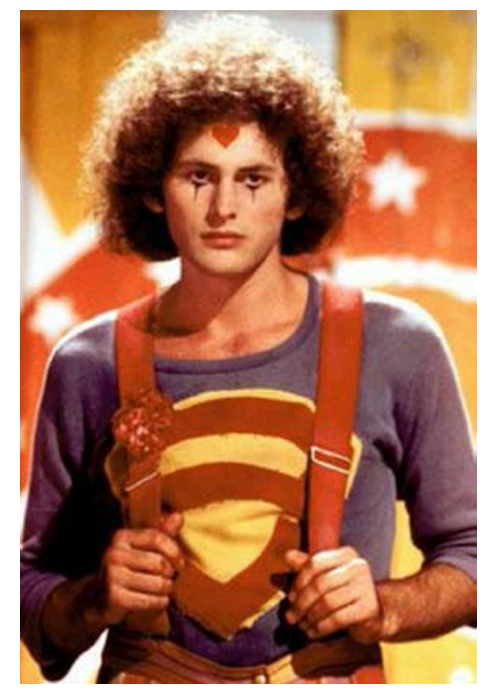

Imagen 8. Victor Garber como Jesús en Godspell.

En ambas películas presenciamos como los movimientos contraculturales habían pasado a convertirse en fenómenos de masas. El carácter casi indie de las obras originales queda plasmado en su versión cinematográfica, como si de dos grandes happenings se tratara, uno en el desierto del Néguev, en Israel, y otro en las calles de Manhattan. En ambos, los actores llegan a las localizaciones como personas que se transformarán para narrarnos la historia de Jesús. En el caso de Jesucristo Superstar, un grupo de jóvenes llega al desierto en un autobús, lo que nos conecta de manera inmediata a la imagen del hippie trotamundos que trascendió más allá de los años de revolución político-social. Como si de la grabación de un documental se tratara, los jóvenes actores descargan el atrezo que van a utilizar, y se preparan, vistiéndose y maquillándose para la ocasión. La película fue rodada en varios parques naturales de Israel, así como en distintas localizaciones de Oriente Próximo, lo que le concede en este sentido un mayor acercamiento a los episodios originales. Además, aunque este filme no contenga líneas textuales presentes en las escrituras, se asemeja más a lo que se establece como real por los Evangelios en los hechos que relata. La veracidad histórica se acompaña de anacronismos que, junto con el argot contemporáneo recogido en la letra de las canciones, restan solemnidad a una narración tan seria como son los últimos episodios de la vida de Jesús.

El carácter histórico que posee Jeuscristo Superstar desaparece por completo en Godspell, que mantiene un vestuario casi accidental, lo que le confiere un carácter más similar a la primera improvisación que se puso en escena. Mientras que en el primero, con su afán por acercarlo a una realidad histórica, similar a la que poseían las grandes producciones bíblicas conocidas hasta el momento, tiene uno mucho más cuidado, que ayuda a identificar a los personajes con rapidez. Los seguidores 

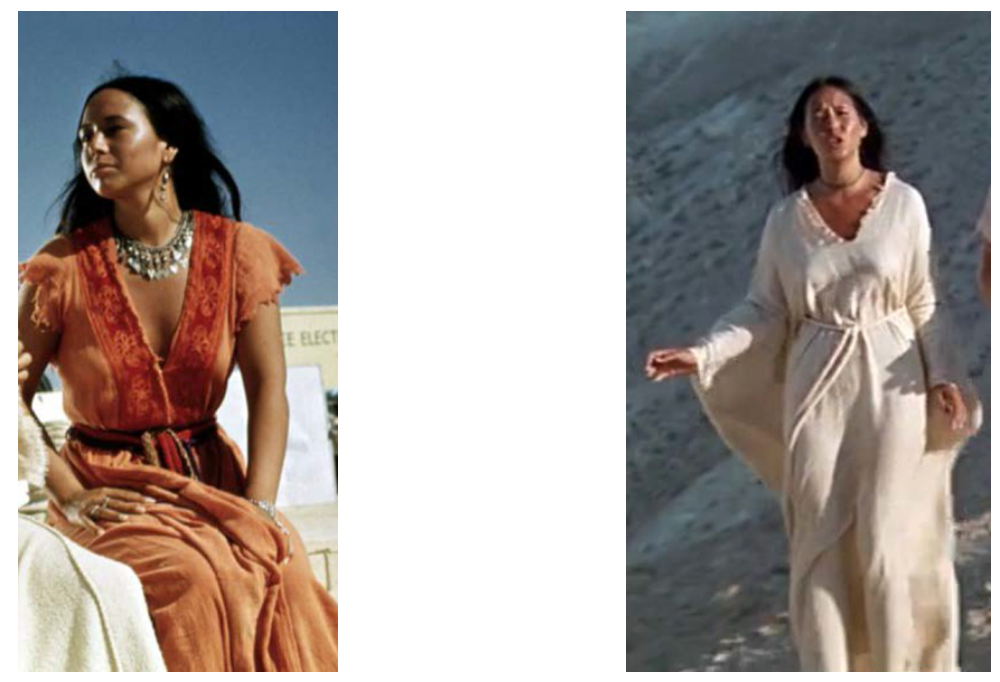

Imágenes 9 y 10. Fotogramas de Jesucristo Superstar. Evolución de María Magdalena.

del Mesías llevan ropas claras, de tonos arenosos, al igual que todos los apóstoles, menos Judas y María Magdalena, que visten en tonos rojizos. El primero termina suicidándose, por lo que no vemos en él el cambio que se aprecia en María Magdalena, que según se acerca el final y por lo tanto la crucifixión, aparece vestida a imagen y semejanza de Jesús, lo que nos lleva a pensar que ha habido un cambio en su forma de seguirlo. A través de las letras de las canciones, especialmente en I don't know how to love him, se cuestiona sus sentimientos hacia Jesús, sin poder identificarlos. Se humaniza así un personaje que durante mucho tiempo se ha identificado con el de una prostituta que ama ciegamente al Mesías. A través de estas letras trasciende el carácter humano también de Jesús, y su gran impacto en María Magdalena, que no comprende cómo un hombre más es capaz de generar tantas dudas en su persona. Por primera vez se cuestiona el amor que profesa hacia él, si es en realidad hacia la magnitud de su persona o sus ideas.

Hacia el final del filme, cuando se produce el cambio de vestuario de María Magdalena (imágenes 9 y 10), su tono cambia completamente. En esta última canción, Could we start again, please?, acompañada por Pedro, parecen llegar a comprender el mensaje de Jesús y piden que termine todo y volver a empezar. Podemos ver, en estos dos personajes, los discípulos que llevarían las enseñanzas del Mesías. María Magdalena pasa de ser la amante de un hombre para abrazar las ideas que trasmite y llevarlas a cabo, es aquí cuando hace un llamamiento al mundo. No hace falta sacrificarse o morir llevando el mensaje de un ente superior. Esto podría verse como un paralelismo con la clase política y los jóvenes que como consecuencia son utilizados como los mensajeros en la Guerra de Vietnam. Estos personajes representarían a los jóvenes que deciden frenar las injusticias y piden volver a empezar 
de nuevo, en un mundo en el que se pueda llegar al entendimiento sin violencia. Cuando Jesús se retira al huerto, una vez que envía a Judas a que lo traicione, escuchamos también a través de su canción cómo apela directamente a Dios en busca de respuestas por su muerte. De alguna manera se resiste a pensar que su crucifixión realmente pueda servir como motor de cambio en la sociedad. Jesús es el mensajero que tras cumplir su cometido muere y es olvidado; nuevamente aquí, podríamos relacionarlo con la situación que se vivía en el conflicto armado de Vietnam. Como muchos jóvenes, Jesús se pregunta si realmente merece la pena, si va a cambiar algo.

Otra de las grandes diferencias que encontramos en estos dos filmes queda patente al escuchar las canciones. En este sentido, el origen de los musicales que se llevan a la pantalla se pone de manifiesto. Jesucristo Superstar fue concebido en un principio como un álbum conceptual, por lo que las canciones debían soportar el peso de la trama. Es aquí donde se aprecia el gusto por la ópera de Lloyd Webber, ya que intercala grandes baladas de los solistas con canciones plenamente corales. Los personajes, además, se definen en función de las voces. Como en las óperas clásicas, tenemos por un lado a Jesús, que como protagonista es tenor, Judas es interpretado por otro tenor, y María Magdalena por una mezzosoprano; repitiendo los patrones vocales que encontramos en Verdi o Puccini. Es llamativo cómo Lloyd Webber coloca en la voz de un bajo el personaje de Caifás, siendo identificado así desde el principio como el antagonista frente al tenor. Teniendo en cuenta su origen como obra puramente vocal, en el filme se puede apreciar cómo el carácter de los personajes se deja entrever en las líneas melódicas que los acompañan, siendo uno de los más identificables el tema que acompaña a María Magdalena, presente en todas sus canciones.

En el caso de Godspell, nos encontramos ante una obra que no pierde su origen puramente teatral, ya que lo verdaderamente importante no se refleja en las canciones, sino en la parte dialogada, lo que la asemeja al singspiel alemán. En este caso, queda patente que las canciones refuerzan la trama, y en algunas ocasiones sostienen el avance de la narración. Como es el caso del tema God Save the People, que aparece al comienzo de la película; esta canción establecerá el tono que va a seguir la narración. Por primera vez los jóvenes se preocupan por el futuro y el efecto de sus acciones en el desarrollo social, tanto dentro como fuera del país. Siendo una generación que se vio afectada por los efectos de la II Guerra Mundial y la Guerra de Vietnam, ven en perspectiva que la lucha entre iguales no lleva a ninguna parte, y lo único que podría salvar a esta sociedad corrompida es el perdón de Dios.

Mientras que en la obra de Lloyd Webber predominan las baladas frente a los números corales, Godspell podríamos definirlo como un gran trabajo coral. El personaje de Jesús lidera la narración, pero se apoya en todos los demás, que podríamos identificar como sus discípulos. Según las memorias de Stephen Schwartz, el origen de la mayoría de las canciones se encuentra en los himnos de la Iglesia episcopal, así como en algunos salmos. En el tema Day by day, vemos cómo funciona la estructura repetitiva de los salmos, una única estrofa se canta primero por un único personaje al que se le va uniendo el coro poco a poco, de esta manera el espectador se ve introducido en la dinámica musical y la melodía pegadiza hace que este tema se convierta en un recurrente. La letra es sencilla, igual que las tres cosas que piden 
los fieles, que son ver al Mesías más claramente, amarlo de una manera más cariñosa y por lo tanto seguirlo más de cerca.

Es precisamente la cercanía que presenta en este filme el personaje de Jesús lo que hace que el espectador se sienta parte de la narración. A pesar de que Jesús no bautiza a sus seguidores, de alguna manera se podría asimilar al momento en el que les pinta la cara como símbolo de pertenencia a la comunidad. La relación de los discípulos hacia su mesías se va estrechando a lo largo de la narración, mientras que en Jesucristo Superstar ésta parece deteriorarse con el paso del tiempo. Otra de las diferencias que encontramos entre ambas películas es que, mientras la segunda transcurre en lo que parece un periodo de tres días, Godspell sucede a lo largo de un día. De manera que, al llegar la noche, Jesús borra la pintura de la cara de sus seguidores a modo de despedida y se prepara para la última cena. Es en este momento cuando Judas se marcha instigado por Jesús, para denunciarlo frente a la policía, que al llegar lo encuentra crucificado de manera ficticia a una valla. Podríamos pensar que éste es el final del filme, como lo es en el caso de Jesucristo Superstar; sin embargo, éste no es más que el comienzo de una nueva vida para todos los jóvenes. Como si de un sueño se hubiera tratado, todos regresan a la realidad tras vivir una experiencia reveladora, todos menos Judas.

En este día de reflexión todos ponen en perspectiva la importancia de la colaboración y la vida en comunidad, comenzaron siendo extraños que tenían cada uno un modo de vida completamente distinto, pero acaban siendo compañeros. La religión es utilizada como pretexto para cuestionar el modo de vida establecido por una sociedad que no propicia el encuentro, ni la vida en comunidad. Las calles de Manhattan plagadas de trabajadores que se cruzan día a día se muestran como una jungla de asfalto en la que nadie conoce al vecino; sin embargo, estos jóvenes vuelven cargando a Jesús con ellos, para romper con la egoísta sociedad obcecada con el desarrollo personal.

Tanto Godspell como Jesucrsito Superstar no pierden en ningún momento su carácter performativo, en ésta última, según avanza el film, poco a poco vamos olvidando que nos encontramos ante una representación de la vida Cristo, y esto es en parte porque se incorporan elementos de la vida contemporánea, junto con situaciones que nos llevan a un lugar indeterminado del pasado. Uno de los episodios que se recrean es la entrada de Jesús en el templo, convertido en un mercado, en el que lo que importa es el dinero, las armas y la vanidad, reflejada a través de los numerosos espejos y postales turísticas. También se nos muestra a una sociedad corrompida por las drogas y las armas, que aparecen como un objeto más a la venta. Se nos presentan así todos los pecados capitales del mundo contemporáneo, en un entorno de ruinas romanas, pertenecientes a la antigua ciudad de Audat (imagen 11).

A pesar de las diferencias que se nos plantean entre estas dos producciones, ambas utilizan las sagradas Escrituras como referencia. Mientras una nos trasmite las enseñanzas recogidas en los Evangelios, la otra, de una manera realista y más humana, nos muestra el ascenso y la caída de Jesús. Al poseer la misma fuente escrita como punto de partida, podemos encontrar también similitudes, y éstas están presentes en los episodios más importantes de la vida de Jesús según se recoge en el Nuevo Testamento. La última cena, la traición de Judas y la crucifixión son 


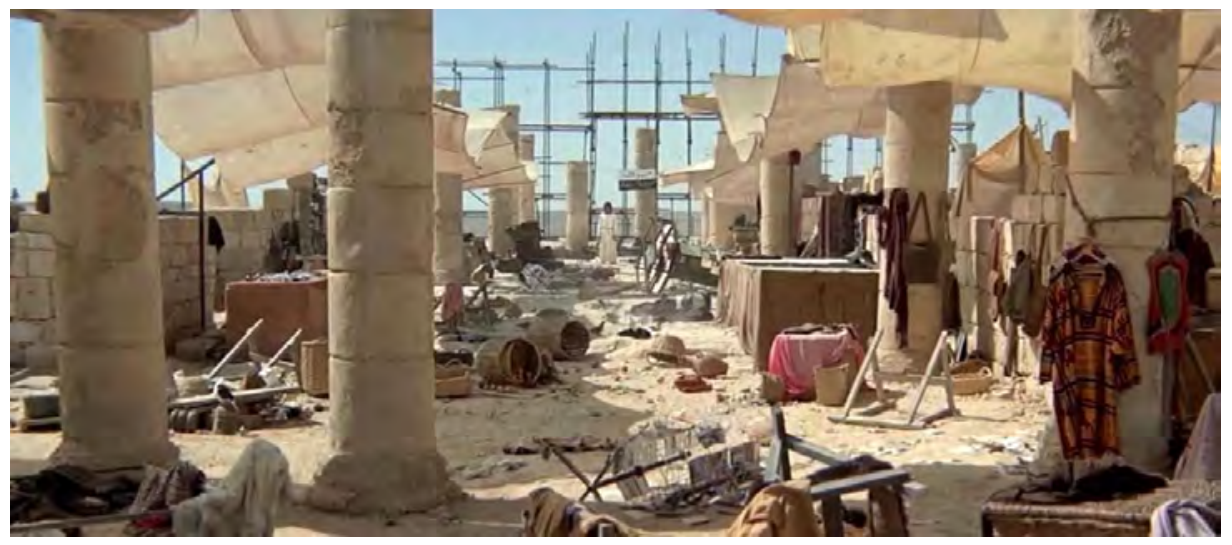

Imagen 11. Fotograma de Jesucristo Superstar. Mercado destruido por Jesús.

representadas en las dos películas. En Jesucristo Superstar, se recrea con todo detalle la pintura más famosa de Da Vinci, mientras que en Godspell se trata, más bien, de una última cena colectiva tras las aventuras vividas. Algo similar ocurre con el momento de la crucifixión, mientras en la primera es recreada como si de una pintura barroca se tratara, la segunda nos la muestra de una forma mucho más naíf. En esta última el personaje de Jesús es atado, en cruz, a una valla con lazos rojos, y en este caso, es la policía la que viene a detenerlo de la misma manera que en su momento miles de jóvenes que abrazaban la ideología hippie fueron censurados por las fuerzas del orden.

Tras ello, en Godspell los jóvenes vuelven a la realidad neoyorquina cargando a Jesús, mientras que en Jesucristo Superstar una vez que Cristo es crucificado, los jóvenes, tras vivir esta experiencia de carácter religioso, regresan al autobús que los dejó en el desierto. Como si no hubiera ocurrido nada regresan, dejando atrás la historia narrada.

Las creencias religiosas tuvieron una gran importancia durante los años de la Contracultura, los jóvenes buscaban aferrarse a algo que, a la vez, los alejara de los oficios convencionales que se habían establecido como tradicionales. Esto llegó a las pantallas, de la misma manera que se extendió la moda y la estética de lo hippie. Pronto la cultura de masas absorbió todo lo que recordaba a los jóvenes irreverentes, para poder captar al público juvenil consumidor de estos nuevos productos. La industria cinematográfica vio en este público su opción de seguir viva, y por ello aprovechó la fama de los musicales independientes, diferentes y novedosos que se ponían sobre los escenarios. La Contracultura marcó el devenir de una juventud que, a partir de ese momento, empezó a cuestionarse su papel en la sociedad y la vigencia de los modelos establecidos. Su ejemplo traspasó fronteras, no sólo geográficas, sino temporales. 


\section{BIBLIOGRAFÍA}

AjA, L.R. (2007): La Contracultura ¿Quéfue? ¿Qué queda?, Madrid, Mandala Ediciones.

Belton, J. (2005): American cinema, american culture, Nueva York, McGrawHill.

Boff, L. (1978): Teología del cautiverio y la liberación, Madrid, Ediciones Paulinas.

Brown, J.D. (1967): The Hippies, Nueva York, Time Inc.

Cerchiari, L. (2017): Storia del Musical, Teatro e cinema da offenbach alla musica pop, Milán, Bompiani.

Charters, A. (2001): Beat down to your soul: What was the Beat Generation?, New York, Penguin.

Coок, D.A. (2000): Lost Ilusions, American cinema in the shadow of Watergate and Vietnam 19701979, Los Ángeles, University of California Press.

Coupe, L. (2007): Beat sound, Beat vision, Manchester, Manchester University Press.

Cusic, D. (2002): The Sound of Light: A History of Gospel and Christian Music, Wisconsin, Hal Leonard Corporation.

Duberman, M. (1994): Stonewall, Nueva York, Plume.

Epstein, B. (1991): Political protest and cultural revolution: nonviolent direct action in the 1970s and 1980s, Berkeley, University of California Press.

Feuer, J. (1982): The Hollywood Musical, Msdrid: Verdoux.

Fierdan, B. (1963): The Feminine Mystique, Nueva York, W.W Norton \& Company.

Flowers, R.B. (1984): Georgia, Religion in Strange Times: The 1960s and 1970s, Mercer University Press.

FRANK, T. (1997): The conquest of cool : business culture, counterculture, and the rise of hip consumerism, Chicago, University of Chicago Press.

Giere, C. de (2008): Defying Gravity: The creative career of Stephen Schwartz, Nueva York: Applause.

Gutiérrez, G. (1971): Teología de la liberación, Lima, Universitaria S.A.

Hall, S. (1970): Los hippies: una contra-cultura, Barcelona, Anagrama.

Herberg, W. (1960): Protestant-Catholic-Jew : an essay in American religious sociology, Nueva York, Anchor Books.

Herberg, W. (1960): Protestant-Catholic-Jew : an essay in American religious sociology, Nueva York, Anchor Books.

Holmes, J.C. (1952): «This is the Beat Generation», The New York Magazine, 16 noviembre, p. 10.

Hurault, B. (2002): La Nueva Biblia Latinoamericana, 98 ed., Madrid, Verbo Divino.

Johnson, R.C. \& Grace, N.M. edits. (2002): Girls who wore black, New Jersey, Rutgers University Press.

Jones, J.B. (2003): Our Musicals, Ourselves: A Social History of the American Musical Theatre, Massachusetts, University Press of New England.

Kerouac, J. (1995): «Lamb, no lion», en A. Charters, ed. The Portable, Nueva York, Viking Penguin, p. 568.

Knight, B. (1996): Women of the Beat Generation: The Writers, Artists and Muses at the Heart of a Revolution, California, Conari Press. 
López, A.B. (2018): Más allá del arcoíris, Madrid, Diábolo.

Macan, E., (1997): Rocking the Classics: English Progressive Rock and the Counterculture, Oxford, Oxford University Press.

Miret, R. \& Balagué, C. (2009): Películas Claves del cine musical, Barcelona, Robinbook.

Moretta, J.A. ( 2017): The hippies: a 1960's history, Carolina del Norte, McFarland \& Company.

Oppenheimer, M. (2003): Knocking on Heaven's Door,American Religion in the age of Counterculture, Nueva York, Yale University Press.

Price, R.M. (2011): Jesus Christ Superstar, s.l., Ebookit.

Richardson, T. (2012): The Rise of Youth Counter Culture after World War II and the Popularization of Historical Knowledge: Then and Now., Columbia, s.n.

Richards, S. (1979): Great Rock Musicals, Nueva York, Stein and Day.

Rorabaugh, W. ( 2015): American Hippies, Cambridge, Cambridge University Press.

RoszaK, T. (1973): El nacimiento de una contracultura, Barcelona, Kairós.

Rubin, J. (2018): ;Hazlo!, Escenarios de la revolución del 68, Barcelona, Blackie Books.

Snelson, J. (2004): Andrew Lloyd Webber, Connceticut, Yale University Press.

Sobrino, J. (1982): Jesús en América Latina, su significado para la fe y la cristología, Cantabria, Sal Terrae.

SteIn, D.L. (1969): Living the revolution; the Yippies in Chicago, Indianapolis, The Bobbs-Merrill Company.

Turner, V. (1969): The Ritual Process, structure and anti-structure, Ithaca, New York, Cornell Paperback.

VV. AA. (2002): Genre and contemporary Hollywood, London, British Film Institute.

Waldman, A. ed. (1999): The beat book : writings from the Beat Generation, Boston, Shambhala.

Webber, A.L. (2018): Unmasked: A memoir, Londres, Harpper-Collins Publisher.

Weinstock, J. (2007): The Rocky Horror Picture Show, Londres, Wallflower Press.

Wollman, E.L. (2006): The Theater Will Rock: A History of the Rock Musical, from Hair to Hedwig, Michigan, The University of Michigan Press.

\section{Filmografía}

Godspell (David Greene, 1973).

Hair (Miloš Forman, 1979).

Howl (Aullido, Rob Epstein y Jeffrey Friedman, 2010).

Jesus Christ Superstar (Jesucristo Superstar, Norman Jewison, 1973).

Phantom of the Paradise (El Fantasma del Paraiso, Brian de Palma, 1974).

Quadrophenia (Franc Roddam, 1979).

The Rocky Horror Picture Show (Jim Sharman, 1975).

Tommy (Ken Russel, 1973).

Woodstock (Michael Wadleigh, 1970). 
